\title{
Biomaterial Design Strategies for the Treatment of Spinal Cord Injuries
}

\author{
Karin S. Straley, ${ }^{1}$ Cheryl Wong Po Foo, ${ }^{2}$ and Sarah C. Heilshorn ${ }^{3}$
}

\begin{abstract}
The highly debilitating nature of spinal cord injuries has provided much inspiration for the design of novel biomaterials that can stimulate cellular regeneration and functional recovery. Many experts agree that the greatest hope for treatment of spinal cord injuries will involve a combinatorial approach that integrates biomaterial scaffolds, cell transplantation, and molecule delivery. This manuscript presents a comprehensive review of biomaterial-scaffold design strategies currently being applied to the development of nerve guidance channels and hydrogels that more effectively stimulate spinal cord tissue regeneration. To enhance the regenerative capacity of these two scaffold types, researchers are focusing on optimizing the mechanical properties, cell-adhesivity, biodegradability, electrical activity, and topography of synthetic and natural materials, and are developing mechanisms to use these scaffolds to deliver cells and biomolecules. Developing scaffolds that address several of these key design parameters will lead to more successful therapies for the regeneration of spinal cord tissue.
\end{abstract}

Key words: biomaterials; peripheral nerve injury; regeneration; spinal cord injury; therapeutic approaches for the treatment of CNS injury

\section{Introduction}

$\mathbf{I}_{\mathrm{p}}^{\mathrm{N}}$ NJURIES TO THE SPINAL CORD pose a significant health problem; approximately 12,000 people sustain spinal cord injuries annually in the United States (National Spinal Cord Injury Statistical Center, 2009). Spinal cord injury symptoms can vary in severity and can often be highly debilitating. Despite early beliefs that damaged nerves in the central nervous system (CNS) lacked the intrinsic ability to regenerate, spinal cord nerves have been shown to partially regrow into peripheral nerve grafts (Richardson et al., 1980). This discovery has sparked much interest in the field of spinal cord repair, but to date no single repair strategy has been repeatedly successful in promoting full functional recovery following spinal cord injury. Therefore, clinical treatments are generally limited to reduction of pain and swelling and the prevention of secondary injuries through the administration of antiinflammatory drugs such as methylprednisolone (Bracken et al., 1990).

In this review, we will discuss design strategies for nerve guidance channels and hydrogel scaffolds with implications for spinal cord-injury repair. Many excellent review articles exist that comprehensively detail the chemical and physical properties of the variety of materials currently being investigated for CNS repair (Nomura et al., 2006; Schmidt and Leach, 2003; Willerth and Sakiyama-Elbert, 2007; L.M.Y. Yu et al., 2008; Zhong and Bellamkonda, 2008). Here, we strive to provide an overview of the general design strategies that have been used historically, to highlight especially promising advancements in the development of new materials, and to identify potential opportunities for improved materials for spinal cord-injury treatment. Specifically, we will describe the current benefits and challenges of common material design strategies that have been used for the fabrication of nerve guidance channels and hydrogels, and identify the critical design criteria that are hypothesized to affect the regenerative capacity of these materials. Finally, some of the key scientific and technical hurdles currently limiting the development of materials for spinal cord therapy will be discussed.

\section{Historical perspective}

The development of treatments for CNS injuries, including spinal cord injuries, is greatly complicated by the existence of a highly complex injury environment. Spinal cord nerve injury is normally caused by compression from displaced bone

\footnotetext{
${ }^{1}$ Chemical Engineering Department, Stanford University, Stanford, California.

${ }^{2}$ Materials Science and Engineering Department, Stanford University, Stanford, California.

${ }^{3}$ Materials Science and Engineering Department, Stanford University, Stanford, California.
} 
fragments, disc material, or ligaments. The resultant injury site rarely involves a complete transection, and is often irregularly shaped. Upon spinal cord injury, the native fibroblasts, neuroglia, and endothelial cells create an inhibitory repair environment by contributing to the formation of a glial scar that acts as both a mechanical and chemical barrier to regenerating axons. The presence of a blood-spinal barrier aids in the formation and permanence of the glial scar by slowing the infiltration of macrophages - cells that clear debris (Avellino et al., 1995). In addition to scarring, spinal cord nerves are also highly susceptible to secondary injuries that occur when damaged nerves and blood vessels release biochemicals that inhibit healthy neurons and oligodendrocytes.

In contrast to the CNS, much success has been achieved in repairing injuries to the peripheral nervous system (PNS). The PNS and the CNS possess very distinct cellular environments that respond differently to trauma; the PNS possesses a much more permissive atmosphere for repair than the CNS. This is largely due to the presence of Schwann cells, which secrete growth-promoting cytokines (Bhatheja and Field, 2006; Frostick et al., 1998). For short nerve gaps (less than $\sim 5 \mathrm{~mm}$ ), the severed ends can be sutured back together as long as no tension is created at the injury site (Berger and Mailander, 1991; Ijkema-Paassen et al., 2004). For longer gaps, nerve autografts, or the transplantation of donor sensory nerves, are considered the "gold standard" for repair (Millesi et al., 1972; Pollard and Fitzpatrick, 1973; Seddon, 1963). Autografts contain Schwann cells and neurotrophic factors, and provide mechanical guidance for axons to grow toward their severed distal stumps. However, they are plagued by a limited supply of donor tissue, the necessity of conducting a second surgery, and highly variable results (Mackinnon and Hudson, 1992; Millesi, 1981; Ortiguela et al., 1987). Some of these issues have been addressed by the use of acellular grafts made from both animal and cadaver sources (Hudson et al., 2004; Marmor, 1964). Much focus has been directed to the development of synthetic nerve guidance channels as an alternative to using grafts for repair. Nerve guidance channels bridge nerve gaps and provide directional guidance, a surface for nerve regeneration, and protection from the surrounding environment.

Based on the success of nerve guidance channels in the PNS, researchers have considered using nerve guides to repair spinal cord injuries. However, the physiological differences and increased complexity of the CNS relative to the PNS places different demands on the design of CNS guidance channels. As a result, the optimal design of CNS guidance channels is expected to be quite different from the optimal PNS guidance channels. Furthermore, guidance channels may not even be the most advantageous strategy for spinal cord repair. Due to the complex geometries and partial transections often encountered at spinal cord injury sites, the implantation of a nerve guidance channel may be surgically complicated. Therefore, hydrogel materials that can expand to fill the entire wound site have also been considered for spinal cord-injury treatment (see recent review articles: Nomura et al., 2006; Willerth and Sakiyama-Elbert, 2007; Zhong and Bellamkonda, 2008). Hydrogels can be easily cast into various shapes or injected directly into the wound site for in situ gelation and, once implanted, can provide a scaffold through which nerves can regenerate. The general consensus is that a combinatorial approach involving channels, scaffolds, neurotrophic growth factors, or cells must be taken in order to effectively repair spinal cord injuries (Bamber et al., 2001; Fouad et al., 2005; Nomura et al., 2008b; Taylor and Sakiyama-Elbert, 2006; Tobias et al., 2005; X.M. Xu et al., 1995b; and recent review articles: Benowitz and Yin, 2008; Busch and Silver, 2007; Lu and Tuszynski, 2008). Current approaches for the design and composition of CNS nerve guidance channels and hydrogels will be discussed separately in the following sections.

\section{Nerve Guidance Channels}

Nerve guidance channels have been synthesized from a wide assortment of natural and synthetic polymers (Table 1). The channel serves to prevent the ingrowth of fibrous scar tissue, to concentrate neurotrophic molecules released from the injured nerve stumps, and to direct growth from the proximal to the distal nerve stump (Danielsen et al., 1993; Longo et al., 1983; Lundborg et al., 1982; Williams et al., 1983). The dimensions, material of construction, and luminal components all affect the regenerative capacity of a given nerve guidance channel design; see Figure 1 for a depiction of critical design parameters integral for nerve guidance channel function. Several materials have already been approved by the FDA for use in the repair of short gaps in human peripheral nerves (Table 2) (Schlosshauer et al., 2006). To date, most research involving nerve guidance channels has involved PNS applications. However, encouraging results demonstrating partial CNS nerve regeneration in PNS guidance channels have led to increased interest in their use for spinal cord repair.

Since no material has currently established itself as a clear or dominant choice for either PNS or CNS repair, there is still a large demand for new materials. The choice of material for use in nerve guidance channels has largely been influenced by the underlying regeneration strategy. Central to the choice of regeneration strategy is the distinction between using nondegradable (and generally "bioinert") grafts versus biodegradable (and generally "biointeractive") grafts.

\section{Material design strategies}

Nondegradable materials. Nondegradable channels are made of synthetic materials that offer uniform and controlled synthesis techniques. They also require a less complex design due to the lack of issues such as degradation rate control and toxicity of degradation products. However, the permanent implantation of a nondegradable channel creates a higher risk of inflammation and may result in nerve compression over time, which often necessitates a second surgery to remove the material (Belkas et al., 2005; Mackinnon et al., 1984; Merle et al., 1989). Furthermore, nondegradable materials are almost always inherently non-cell adhesive, limiting their application in more advanced channel designs involving cell transplantation. Despite these inherent limitations, the simplified design and construction of nondegradable channels have made them particularly useful in preliminary studies of CNS nerve repair and have sped up experimental progress through their use both in vitro and in vivo.

Common nondegradable materials that have been used to fabricate nerve guidance channels include silicone, polyacrylonitrile/polyvinylchloride (PAN/PVC), poly(tetrafluoroethylene) (PTFE), and poly(2-hydroxyethyl methacrylate) (PHEMA). Despite several experiments demonstrating the ability of silicone channels to support peripheral nerve re- 


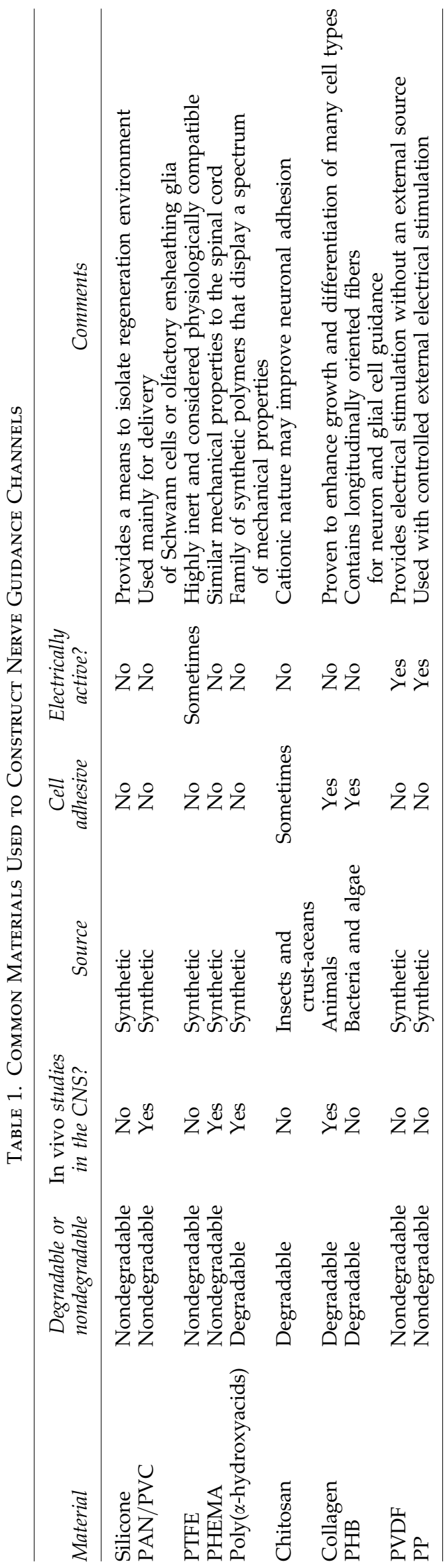

generation in vivo, silicone is not widely considered the material of choice for nerve repair due to its nonporous structure, questions about its toxicity, and the tendency of silicone channels to compress regenerating axons after long-term implantation (Merle et al., 1989). Alternatively, channels constructed from PAN/PVC are semipermeable and are considered structurally stable in vivo (Moon et al., 2006; X.M. Xu et al., 1999). This has made PAN/PVC a potential choice for more advanced channel designs, often including the delivery of Schwann cells or olfactory ensheathing glia (Moon et al., 2006; X.M. Xu et al., 1999). In spite of its biocompatibility, PAN/PVC is not inherently cell adhesive, and most applications have used a Matrigel coating to encourage cell adhesion. Matrigel's origin as a mixture of proteins secreted from mouse tumor cells makes it problematic for use in humans (see description in the section "Hydrogels," subsection "Physically Crosslinked Materials").

PTFE was chosen as a potential material for channel design due to its approval for use in humans and its previous use in a variety of medical devices (Pogrel et al., 1998; Stanec and Stanec, 1998a). PTFE channels possess a pronounced hydrophobicity making them highly anti-adhesive. Their antiadhesive nature both minimizes the resultant immune response upon implantation and limits their application to act as only simple scar barrier systems. PTFE channels have shown mixed results in vivo for the improvement of PNS injuries (Pitta et al., 2001; Pogrel et al., 1998; Stanec and Stanec, 1998b), and are not being widely considered for CNS therapies.

PHEMA is currently the most actively researched nondegradable material for use in nerve guidance channels. It possesses soft, tunable mechanical properties and can be easily molded into a tubular shape with controlled dimensions, morphology, and permeability (Dalton et al., 2002). Also, PHEMA synthesis is carried out at low temperatures and without toxic solvents, thus allowing for the incorporation of bioactive compounds into the polymer scaffold (Tsai et al., 2004). Despite these benefits, PHEMA channels have demonstrated variable results in studies evaluating toxicity and mechanical strength (Belkas et al., 2005; Smetana et al., 1987). Progress has been made to address the mechanical strength issues through copolymerization with hydrophobic methacrylate monomers and increasing tube wall thickness (Dalton et al., 2002). Through inclusion of an internal matrix, PHEMA guidance channels have been shown to support axonal regeneration in injured rat spinal cords (Tsai et al., 2006). Even though some positive results have been seen with nondegradable channels such as those constructed with PHEMA, the simple designs of these channels are generally considered less suitable for the more demanding regeneration environments encountered in the CNS, as well as longer gaps in the PNS. As a result, nondegradable channels are not the focus of most current research efforts.

Degradable materials. Degradable channels circumvent the need to either permanently implant a nondegradable material or remove a nondegradable material with a second surgery. They also present a smaller risk of nerve compression, since they degrade as the nerve regenerates. Degradable channels can be composed of either natural or synthetic materials, but the majority of degradable channels come from natural sources. Materials harvested from natural sources can present problems in uniformity and controlled fabrication of 


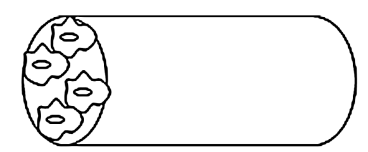

Cell Adhesion

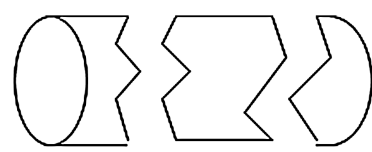

Biodegradable

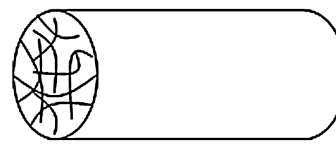

Internal Matrix

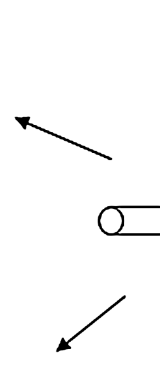

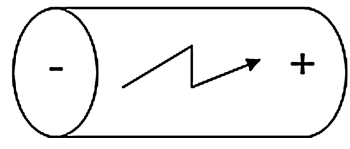

ElectricallyActive
Porosity

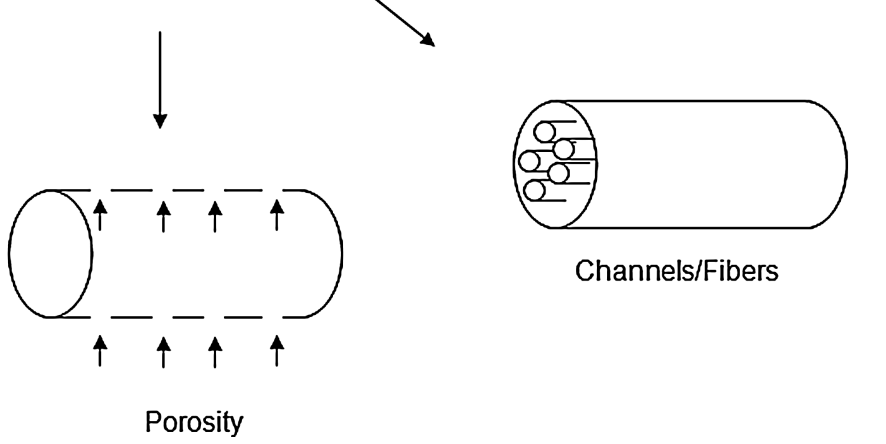

FIG. 1. Key design elements in the construction of nerve guidance channels (adapted from Huang and Huang, 2006).

nerve guides due to batch-to-batch variability. Furthermore, many naturally harvested materials are difficult to purify, and incomplete purification can result in immune-system activation by the implant. Degradable channels also require more complex designs, since their degradation products must be nontoxic and their degradation rates must be tuned to match the regeneration rate. Natural materials are often more inherently adhesive to neurons and glial cells, making them candidates for more "biointeractive" designs. Some common degradable materials that have been studied for use in nerve guidance channels include the polymer family of $\operatorname{poly}(\alpha$-hydroxyacids), collagen, chitosan, and poly ( $\beta$-hydroxybutyrate) (PHB).

The family of poly( $\alpha$-hydroxyacids) include synthetic polymers and copolymers such as poly(glycolic acid) (PGA), poly(lactic acid) (PLA), poly(lactic acid-co-glycolic acid) (PLGA), and poly(lactide-co-caprolactone) (PLCL). Several mechanisms have been identified for controlling the degradation and mechanical properties of these polymers including varying the ratio of monomer units, the stereochemistry of the monomer units (either D- or L-form), and the molecular weight distribution of chains. Since poly $(\alpha$-hydroxyacids) degrade in vivo by hydrolysis and produce acidic degradation products that result in a transient $\mathrm{pH}$ decline, only a limited amount of the polymer can be implanted (Park et al., 1995). Both PGA and PLCL have been approved by the FDA for use in the repair of human peripheral nerves, and this success has inspired investigation of their use in CNS repair (Gautier et al., 1998; Oudega et al., 2001).

Collagen's natural abundance in the connective tissue of animals makes it an attractive material for the construction of nerve guidance channels. It is typically formed into guidance channels through the addition of chemical crosslinking agents, which allows direct control over the strength of the channel and the degradation rate, but also introduces issues with toxicity of the crosslinking agent (Itoh et al., 2002). Collagen has been shown in vitro to enhance the growth and differentiation of many cell types. The main drawback to using collagen is that it is difficult to harvest and cleanly purify in an inexpensive and reproducible manner. If purified cleanly, collagen from mature bovine sources is nonimmunogenic in humans; however, collagen from nonhuman sources can cause an immune response when purified using less stringent protocols (Wahl and Czernuszka, 2006). The study of collagen in nerve repair has resulted in the FDA approval of two collagen peripheral nerve guidance channel designs and their investigation for use in CNS therapies (KassarDuchossoy et al., 2001; Liu et al., 1998).

Chitosan is a natural polysaccharide produced from the $\mathrm{N}$-deacetylation of chitin, one of the most abundant natural biopolymers. Interest in chitosan for channel design largely stems from its capacity to exhibit tunable properties through variation in the acetyl group content. Specifically, the rate of degradation, compressive strength, and cell adhesivity of the material have been shown to be controlled by the amount of acetylation (Freier et al., 2005b). Furthermore, the cationic nature of chitosan polymers is believed to contribute to enhanced neuronal adhesion and interaction with anionic growth factors and compounds present in the extracellular matrix (ECM) (Freier et al., 2005a). Some drawbacks to using chitosan are that it has shown issues with low mechanical strength and it is insoluble in many common solvents, which prevents easy processing into channels (Freier et al., 2005a; Yamaguchi et al., 2003b). However, novel fabrication techniques have been developed recently to address these pro- 


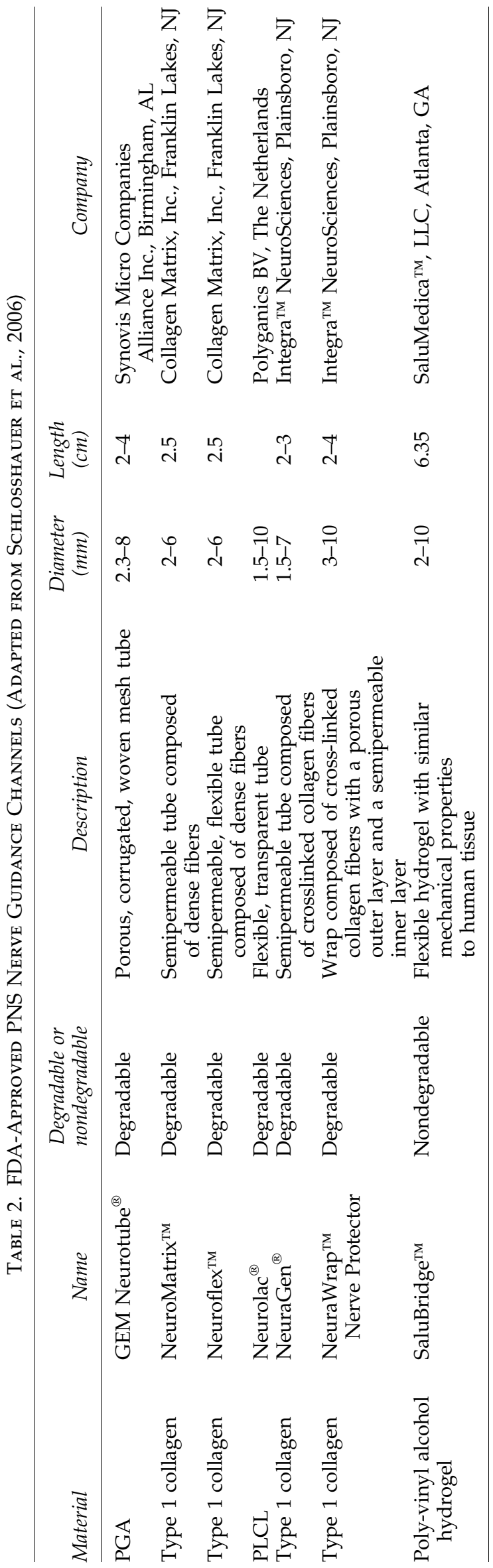

cessing challenges, including forming gels at high $\mathrm{pH}$ and deacetylating chitin tubes formed from hollowed crab tendons (Kofuji, 2003; Yamaguchi et al., 2003b). Recently, chitosan scaffolds have been used to transplant viable peripheral nerve grafts, neural stem cells, and neural progenitor cells into rat spinal cords, resulting in increased axonal regeneration (Nomura et al., 2008a, 2008b).

PHB introduces the unique feature of longitudinally oriented fibers into a channel construction material. These fibers are hypothesized to provide alignment and physical guidance to growing neurons and glial cells, and have been shown to separate gradually after implantation resulting in increased physical support for growing neurons (Young et al., 2002). The slow absorption of PHB in vivo may be a beneficial feature for nerve repair since it remains as a support for regeneration over a long period of time (Ljungberg et al., 1999). Because PHB degrades by hydrolysis and enzymatic action to produce $\beta$-hydroxybutyric acid, its slow degradation rate also limits the accumulation of acidic degradation products compared to poly- $\alpha$-hydroxyacids (Ljungberg et al., 1999). PHB possesses good tensile strength and elasticity, which prevents compression of growing neurons and has been shown to promote regeneration in larger PNS injury gaps (Young et al., 2002).

Electrically active materials. As discussed above, the choice between a biodegradable or nondegradable material is a key design strategy when developing new biomaterials for nerve guidance channels. A second design strategy that is being explored is the use of electrically active materials. It is generally believed that as tissues develop or regenerate, electrically charged materials in the ECM generate electric fields that act as signals to promote and control growth, remodeling, and protein adsorption (Fine et al., 1991; Kotwal and Schmidt, 2001). It has been shown in vitro that neurite extension is enhanced by, and growth directionality can be controlled on, electrically active materials (Patel and Poo, 1982). In vivo electrical stimulation has been shown to have a positive effect on the functional recovery of motor and CNS nerves (Borgens et al., 1981; Nix and Hopf, 1983).

Constructing nerve guidance channels with electrically active materials offers the ability to deliver localized electrical stimuli at an injury site while also providing a physical surface for regrowth. The three main types of electrically active biomaterials under consideration are polymers with a quasipermanent surface charge (electrets), polymers that generate an electric charge upon applied mechanical stress (piezoelectrics), and electrically conducting polymers. The most widely investigated electrically active materials for nerve repair are poly(tetrafluoroethylene) (PTFE), polyvinylidene fluoride (PVDF), and polypyrrole (PP). While these electrically active materials are generally non-cell adhesive and nondegradable, efforts are underway to improve these properties (Rivers et al., 2002; Wan et al., 2005).

Electret materials, such as PTFE, and piezoelectric materials, such as PVDF, have the benefit of not requiring an external source for electrical stimulation. Charged forms of PTFE have resulted in the regeneration of higher quantities of myelinated axons relative to its noncharged form (Valentini et al., 1989). Materials constructed from the piezoelectric form of PVDF have also resulted in enhanced neurite growth both in vivo and in vitro when compared to the nonpiezoelectric form (Fine et al., 1991). In contrast, PP is a nondegradable conducting 
polymer, which offers the potential to apply controlled, external electrical stimulation to growing neurons (Schmidt et al., 1997). In order to fabricate a degradable alternative to PP, pyrrole-thiophene oligomers have been linked together with hydrolyzable esters (Rivers et al., 2002). Also, blends of PP with chitosan or hyaluronic acid are being investigated to create conducting materials with more biocompatible properties (Collier et al., 2000; Wan et al., 2005). Several variants of PP nerve guidance channels have been tested for in vivo biocompatibility, but future work needs to be done to determine the efficacy of these channels in conjunction with external electrical stimulation (X.D. Wang et al., 2004).

\section{Critical design parameters}

Mechanical strength. When designing nerve guidance channels, it is of great importance to address their mechanical strength, since channel collapse and obstruction of nerve regeneration is a common occurrence in preclinical testing (Belkas et al., 2005). External factors that contribute to channel collapse in vivo include degradation, repetitive compressive forces, and degradation of the material by specialized cells in the body such as macrophages (Belkas et al., 2005). For example, nerve channels constructed from the copolymerization of PHEMA and methyl methacrylate (PHEMA-MMA) exhibited a bimodal recovery response in which the tubes that did not collapse resulted in regeneration close to that of autografts, while the collapsed tubes resulted in little recovery (Belkas et al., 2005). Several approaches have been taken to control the mechanical strength of nerve guidance channels, including crosslinking, coil-reinforcement, and tuning the material composition.

Modifications to the extent of crosslinking within a material can be used to directly control the initial mechanical strength of a channel (Itoh et al., 2002). The mechanical properties of a given channel can be tuned through the application of either surface or bulk crosslinking techniques. The surface crosslinking approach naturally uses less crosslinking agent and can, therefore, help reduce complications resulting from use of potentially cytotoxic crosslinking agents. In addition to affecting the initial mechanical strength of the material, the degree of crosslinking also offers a mechanism to tune channel degradation rate; more heavily crosslinked materials are more resistant to degradation (Itoh et al., 2002).

Alternatively, coils have been introduced into the walls of nerve channels to provide reinforcement (Katayama et al., 2006). For example, PHEMA-MMA channels containing poly-caprolactone coils showed greater patency than nonreinforced channels, and resulted in regeneration results similar to autografts (Katayama et al., 2006). Chitin tubes have also been modified to include poly(lactide-co-glycolide) coils in order to increase their mechanical strength (Freier et al., 2005a). Finally, the mechanical properties of a material can be modified by altering its chemical composition. Specific examples include apatite addition to chitosan tubes (Yamaguchi et al., 2003a), chitin addition to chitosan (Y.M. Yang et al., 2004), and the incorporation of hydrophobic methacrylate monomers into PHEMA (Dalton et al., 2002); each of these additions resulted in an increase in the mechanical strength of the walls. Some believe that simply strengthening the walls of nerve guidance channels to make them more rigid can have negative consequences by creating a mismatch in mechanical properties between the native tissue of the soft spinal cord and the implant (Dalton et al., 2002; Katayama et al., 2006). Such a mismatch in mechanical properties has been implicated in the failure of implants designed for other tissue engineering applications, including bone and vascular implants (Greenwald and Berry, 2000; Moore et al., 2001). This mismatch in mechanical properties may impede cell migration or neurite extension across the implant-tissue interface and can also directly impact cell phenotype (see the section "Hydrogels," subsection "Mechanical Strength and Degradability" for a more detailed discussion). Of the widely studied synthetic materials, only PHEMA currently has an elastic modulus within the range of native soft spinal cord tissue, while the other materials described above have drastically higher moduli (Belkas et al., 2005).

Cell adhesion. The performance of nerve guidance channels has been further enhanced with more advanced designs that focus on cell adhesion. These designs attempt to mimic the natural environment of nerves in vivo and provide contact-mediated guidance for regeneration (Freier et al., 2005a). Cell attachment onto materials can occur through two routes: (i) nonspecific adsorption and (ii) specific adhesion (Haipeng et al., 2000). Nonspecific adsorption is mainly affected by the surface charge, surface roughness, and surface topography (Curtis and Wilkinson, 1997; Haipeng et al., 2000). Chitosan and polylysine are examples of materials that are believed to exhibit increased neuronal cell adhesion due to their hydrophilic nature and electrostatic interactions (Freier et al., 2005b; Haipeng et al., 2000). Experiments have shown in vitro that increasing the cation content of chitosan through a lower amount of acetylation resulted in greater neuronal cell viability (Freier et al., 2005b). Also, coating chitosan with polylysine or using a chitosan-polylysine mixture has shown good neural cell affinity (Haipeng et al., 2000).

Most of the nerve guidance channel research concerning cell adhesion has focused on specific adhesion. It is thought that channels modified with either proteins or peptides derived from the ECM will more closely mimic the environment in peripheral nerve grafts and result in similar regeneration success. There are two main approaches to achieve specific adhesion on nerve guidance channels: inclusion of full-length proteins (e.g. laminin, collagen, and fibronectin) and linkage of shorter active peptide sequences to the surface of the material (Meiners and Mercado, 2003; Suzuki et al., 2003). Precoating materials with ECM proteins, especially laminin, has shown significant improvement in neural cell affinity and functional recovery (Suzuki et al., 2003). In addition to coating materials with ECM proteins, materials have also been coated with neuronal adhesion molecules to enhance nerve regrowth. Of specific interest is the neuronal cell-adhesion molecule L1, which is known to be expressed in growing axons and Schwann cells during development and regeneration (G. Xu et al., 2004).

Since it is often difficult to purify functional proteins and maintain their activity on the surfaces of channels, it is beneficial to try and mimic their functions with active peptide sequences. Specific functions of several key ECM proteins have been attributed to short peptide sequences such as the YIGSR, RGD, and IKVAV amino-acid sequences in laminin (Meiners and Mercado, 2003). In order to allow the peptides to assume the more natural three-dimensional conformations 
found in intact proteins, they are often linked to materials using spacer groups or incorporated using more extended peptide sequences (Shaw and Shoichet, 2003; Tong and Shoichet, 2001). Both in vitro and in vivo experiments have shown the ability of linking peptide sequences to mimic the function of intact proteins and to enhance neuronal regeneration (Ahmed and Jayakumar, 2003; Suzuki et al., 2003; T.T. Yu and Shoichet, 2005).

Internal matrices. One of the most important advances in the design of nerve guidance channels has been the inclusion of an internal matrix. Internal matrices attempt both to increase the bioactivity of nerve guidance channels and to prevent their collapse. A variety of materials and structures are being investigated as internal matrices, including fibers, channels, and hydrogels; to increase function, these matrices are often supplemented with cell suspensions (Fouad et al., 2005; Nomura et al., 2008b; Novikova et al., 2008) or growthfactor solutions to serve as a drug-delivery mechanism (Bloch et al., 2001; Dodla and Bellamkonda, 2008; Tsai et al., 2006). Longitudinally oriented channels and fibers are thought to mimic the endoneurial tubules naturally found in nerves (Verdu et al., 2002). It is believed that channels and fibers promote regeneration by providing increased surface area to which cells and regenerating axons can attach (Ao et al., 2006; Venugopal et al., 2008). Collagen is one of the most common materials used to make fibers, and has been used both with and without an outer nerve guidance tube (Ceballos et al., 1999; Yoshii et al., 2004). Internal matrix channels also have been formed in PHEMA, agarose, and chitosan using molds and phase separation techniques (Ao et al., 2006; Flynn et al., 2003; Stokols and Tuszynski, 2006).

Alternatively, the internal matrix of a nerve guidance tube can be constructed from hydrogels. These amorphous materials are meant to serve as artificial ECM scaffolds that can provide both contact guidance and biological cues to promote nerve regeneration. Common hydrogel materials being explored as internal matrices for nerve guidance channels include collagen (Chen et al., 2000b; Verdu et al., 2002; Wells et al., 1997), fibronectin (Chen et al., 2000b), Matrigel (Tsai et al., 2006; X.M. Xu et al., 1995a), methylcellulose (Tsai et al., 2006; Wells et al., 1997), agarose (Dodla and Bellamkonda, 2008), and laminin (Chen et al., 2000b; Verdu et al., 2002). Beyond their potential use as internal matrices in nerve guidance channels, hydrogels are also being explored as stand-alone regenerative scaffolds, as described in the next section.

\section{Hydrogels}

Much of the current research activity in spinal cord injury repair is focused on the development of novel hydrogel materials and the modification of these materials to provide a permissive and stimulating environment for nerve regeneration. This is largely due to the inherent flexibility of hydrogel scaffolds. They can be cast easily into different shapes and can be used as space-filling agents, making them more ideal for implantation into complex CNS injury sites within both the spinal cord and brain. Another important attribute of hydrogels is their soft, three-dimensional structure, which mimics the in vivo ECM environment. The three-dimensional structure of hydrogels consists of highly swollen, porous polymer networks that can support the exchange of nutrients with surrounding tissue. To enhance cell regeneration, hydrogel scaffolds are often designed as platforms for the delivery of drugs, growth factors, proteins (or peptide ligands), and cells (see detailed discussions in the sections "Cell Encapsulation and Transplantation" and "Biomolecule Delivery" and the following recent review articles: De Laporte and Shea, 2007; Kretlow et al., 2007; Malafaya et al., 2007; Nomura et al., 2006; Willerth and Sakiyama-Elbert, 2007, 2008; L.M.Y. Yu et al., 2008; Zhong and Bellamkonda, 2008). Most recently, researchers have begun to design more complex hydrogel scaffolds that address issues such as mechanical strength, degradation, cell-adhesivity, and topography (see detailed discussions in the sections "Mechanical Strength and Durability", "Cell Adhesion", and "Scaffold Topography and Microstructure"). Ultimately, the success of hydrogels, as with guidance channels, hinges on identifying the appropriate material with the right chemical and biophysical characteristics to address the critical mechanical, mass transport, and biological design variables inherent to each specific application; see Figure 2 for a depiction of critical hydrogel design parameters, and Table 3 for a list of common materials used to construct hydrogels for potential CNS therapies.

The beneficial regenerative properties seen in hydrogel scaffolds are only useful if they can be effectively implanted at the site of CNS injury. This can be a difficult task, considering the complex geometries, partial nerve transections, and scarring that result from spinal cord trauma. The implantation of hydrogel scaffolds alone or in conjunction with cells, biomolecules, and growth factors can be greatly simplified if the material is injectable. Instead of molding the scaffold into complicated shapes for surgical implantation, an injectable gel can simply fill in the injury cavity and encompass the regeneration site, potentially eliminating the need for major surgery. Injectable hydrogels have been developed to form interconnected structures through physical self-assembly, photo-crosslinking, and chemical/enzymatic crosslinking. Despite the simplified implantation approach offered by injectable hydrogels, these materials possess limitations in the implementation of more complex design strategies that utilize spatial patterning. Therefore, the first choice often made in the design of a hydrogel scaffold is which crosslinking strategy to use.

\section{Material design strategies}

Covalently crosslinked materials. Three-dimensional hydrogel networks are commonly formed by covalently linking polymer chains using either chemical or enzymatic crosslinkers. Chemically crosslinked hydrogels are most often prepared as preformed scaffolds for traditional surgical implantation due to potential toxicity of the crosslinking agent. Care must be taken to test the cytotoxicity of a crosslinking agent thoroughly and to use an appropriate concentration and rinsing protocol. Despite these issues, chemical crosslinking generally offers more direct control over scaffold mechanical properties. As a result, recent efforts have been made to develop biocompatible chemical, enzymatic, and photoreactive crosslinking strategies for use in the fabrication of both preformed and injectable materials.

Two synthetic polymers most known for their ability to mimic the mechanical properties of soft spinal cord tissue are 


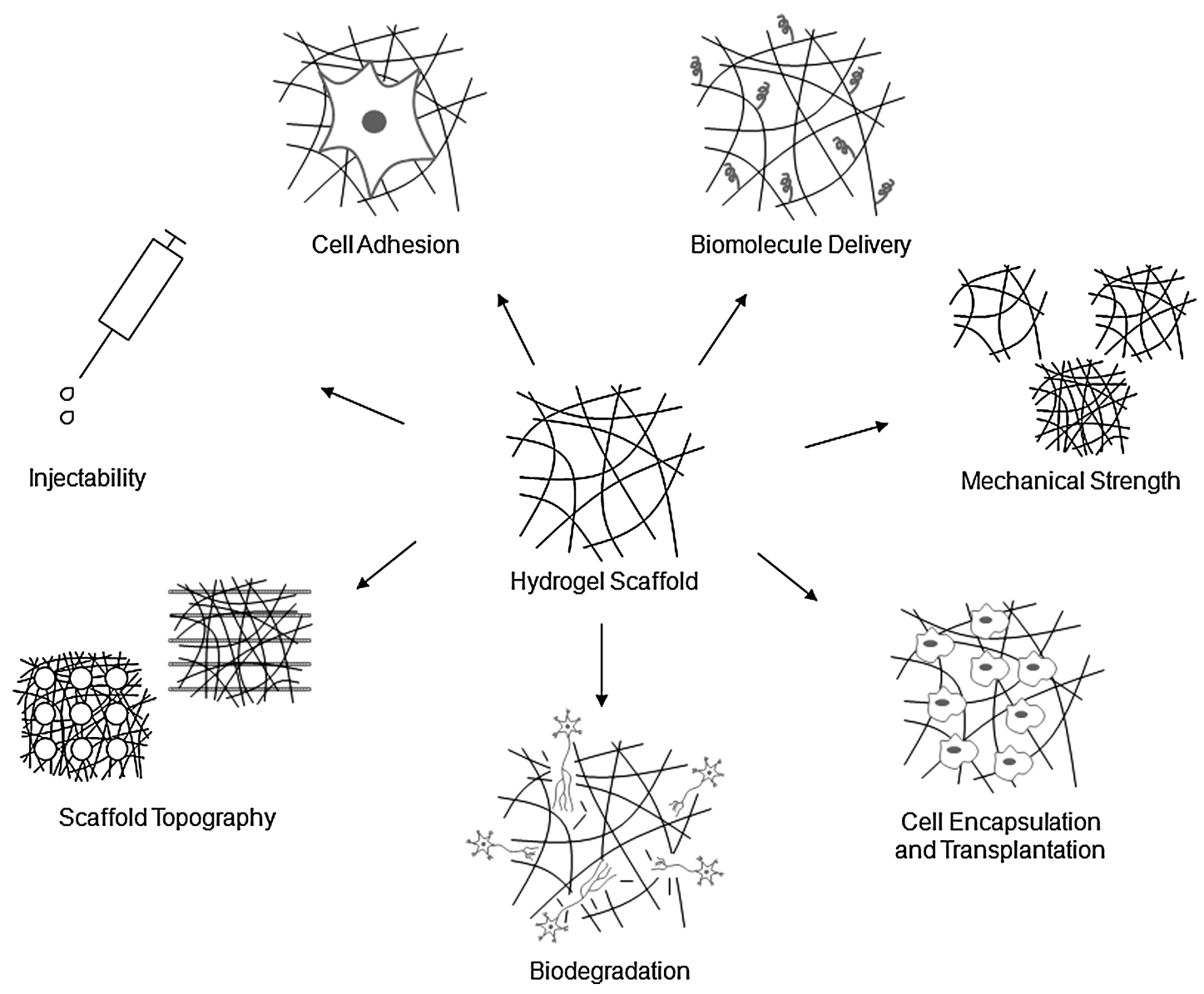

FIG. 2. Key design elements in the construction of hydrogel scaffolds.

PHEMA and poly[N-(2-hydroxypropyl)methacrylamide] (PHPMA). PHEMA hydrogels have been shown to be well tolerated in vivo, to support angiogenesis, and to promote axonal regeneration in rat spinal cord injury models (Bakshi et al., 2004; Hejcl et al., 2008). Its synthesis technique is supportive of biomolecule delivery and is amenable to the fabrication of three-dimensional geometries that may enhance nerve guidance (Bakshi et al., 2004; Flynn et al., 2003). Macroporous PHPMA hydrogels, functionalized with the RGD peptide (Neurogel ${ }^{\mathrm{TM}}$ ), have been shown to promote tissue ingrowth, angiogenesis, and axonal regeneration, and to limit glial scar formation in vivo in transected rat and cat spinal cord injuries (Woerly et al., 2004).

Another synthetic material being investigated for covalently linked CNS hydrogels includes poly(ethylene glycol) (PEG). PEG has been shown to be highly biocompatible, has exhibited neuroprotective behavior, and has enhanced functional recovery following spinal cord injuries in animal models (Bjugstad et al., 2008; Borgens et al., 2002; Luo and Shi, 2007). The basic composition of PEG polymers has been modified to contain either lactide units, which render the polymer hydrolytically degradable, or functional peptide domains, which enhance cell adhesion and polymer degradation (Mahoney and Anseth, 2006; Rizzi et al., 2006).

Natural options for covalently crosslinked hydrogels include collagen, chitosan, hyaluronic acid (HA), fibrin, and dextran. Collagen offers intrinsic biocompatibility, biodegradability, and cell adhesiveness but sometimes needs to be supplemented with growth factors to promote neural cell proliferation and differentiation (Tsai et al., 2006). Crosslinked collagen scaffolds fabricated using chemical crosslinkers and extreme changes in $\mathrm{pH}$ and temperature are generally considered unsuitable for use as injectable materials. However, other collagen scaffold preparation techniques, such as the use of enzymatic crosslinkers or fibrillogenesis (discussed in the section "Physically Crosslinked Materials"), make it possible to gel collagen scaffolds in situ (Grillo and Gross, 1962; O Halloran et al., 2006). Collagen hydrogels have been shown to promote axonal growth and myelination in rat spinal cords, and have been used to minimize scarring following spinal cord laceration in humans (Joosten et al., 1995; Narotam et al., 2004).

Chitosan, a natural polysaccharide, has been widely studied for tissue-regeneration applications due to its biocompatibility and natural abundance. It is most commonly formed into scaffolds through covalent crosslinking with dialdehydes or glutaraldehyde, but through integration with thermosensitive polymers or salt (discussed in the section "Physically Crosslinked Materials"), chitosan has also been used in the formulation of injectable hydrogels (Bhattarai et al., 2005; Cho et al., 2004; Crompton et al., 2006). Although chitosan supports the attachment of cells, coating or blending 


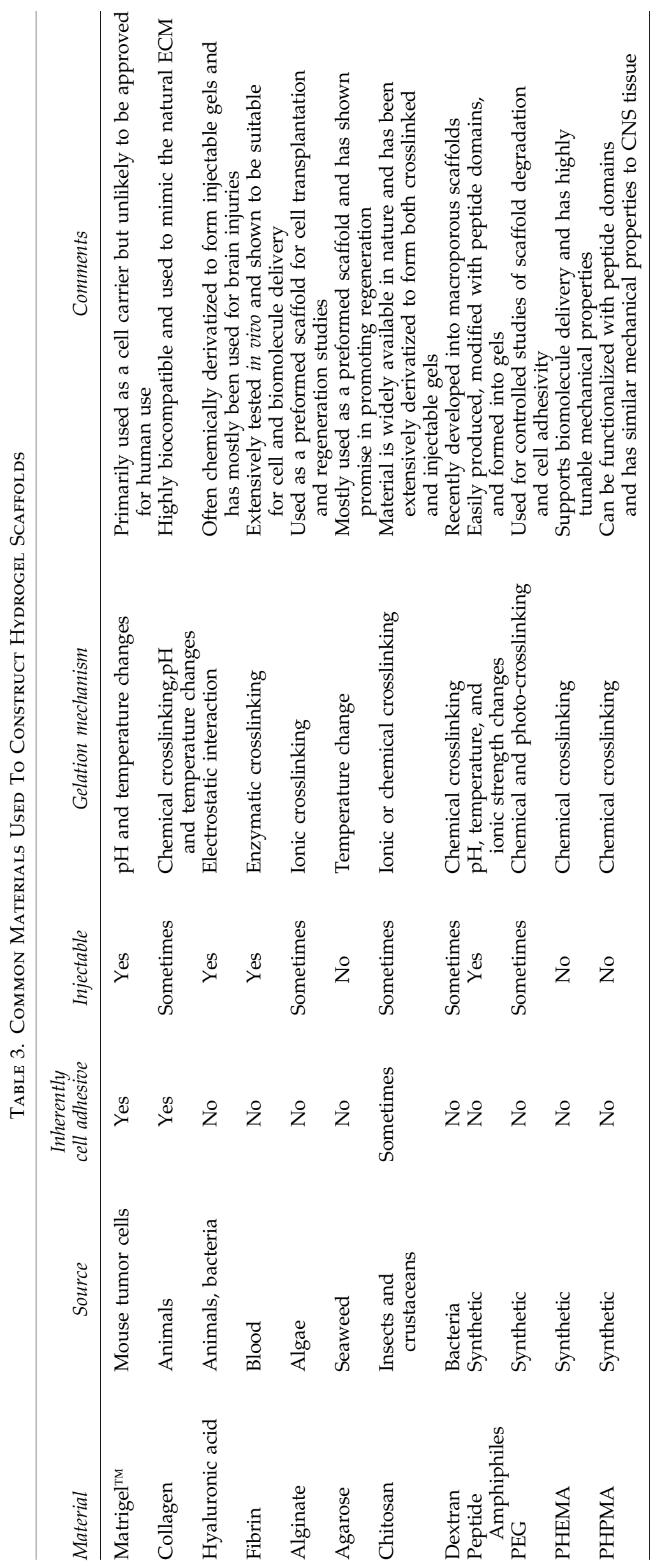


with poly-L-lysine or peptides improves its support for neurons (Cheng et al., 2004; L.M.Y. Yu et al., 2007).

$\mathrm{HA}$ is a nonsulfated glycosaminoglycan (GAG) found naturally in connective, epithelial, and neural tissues, and has been shown to be highly biocompatible. In its natural state, $\mathrm{HA}$ is fabricated into hydrogels using chemical crosslinkers such as glutaraldehyde or carbodiimide. HA has also been widely derivatized to form photocrosslinkable and injectable hydrogels (Gupta et al., 2006; Leach and Schmidt, 2005). With modification to improve cell adhesivity, HA scaffolds have been shown to increase neuronal cell proliferation and outgrowth and to inhibit glial scar formation in rat brains (Cui et al., 2006).

Fibrin (or fibrin glue) consists primarily of fibrinogen and thrombin, which form an enzymatically crosslinked clot upon mixing. It is most often prepared from pooled human plasma, has been extensively tested in vivo, and is used as an injectable material (Petter-Puchner et al., 2007; Taylor and SakiyamaElbert, 2006; Willerth et al., 2006). Fibrin scaffolds have been used for cell transplantation and growth-factor delivery in neural regeneration applications and can be modified with bioactive peptide domains to increase neurite elongation $(\mathrm{Ju}$ et al., 2007; Schense et al., 2000; Taylor and Sakiyama-Elbert, 2006; Tsai et al., 2006).

Dextran, a branched polymer of D-glucose naturally produced by bacterial strains, has recently been used to fabricate macroporous scaffolds. To date, these scaffolds have not been tested in vivo for regenerative capabilities but have been shown in vitro to support adhesion of dorsal root ganglia through modification with bioactive peptides (Levesque and Shoichet, 2006). Further modification of dextran polymers with thiol domains has led to the development of in situ gelling dextran scaffolds (Hiemstra et al., 2007).

An alternative option for the fabrication of covalently crosslinked hydrogels is the use of chemically crosslinked recombinant proteins (Straley and Heilshorn, 2009). This approach combines the benefits of synthetic and natural materials by allowing for direct control over polymer content within a biocompatible protein backbone. Initial characterization of an elastin-like recombinant protein scaffold has demonstrated independent tuning of scaffold mechanical properties, scaffold degradation rate, and cell adhesion of the model neuronal-like PC-12 cell-line (Straley and Heilshorn, 2009).

Physically crosslinked materials. Besides covalent crosslinks, hydrogel networks can be held together by physical interactions. Materials linked through physical forces have a tendency to possess weaker and less tunable mechanical properties. However, they are typically more suitable for use as injectable materials, making them an attractive option for CNS scaffold design. Physically crosslinked materials undergo a solution to gel phase transition due to changes in environmental conditions such as temperature, $\mathrm{pH}$, or ionic concentration. If a material is being designed for in situ gelation, these environmental triggers must be compatible with cells and physiological conditions.

Two examples of physically crosslinked materials not typically suitable for injection are alginate and agarose. Alginate is extracted from brown algae as an acidic block copolymer of 1,4-linked $\beta$-D-mannuronic acid and 1,4-linked $\alpha$-L-gluronic acid. It is crosslinked into a gel using multivalent cations such as $\mathrm{Cu}^{2+}, \mathrm{Ca}^{2+}, \mathrm{Al}^{3+}$, and ethylene diamine, but this nonphysiological gelation environment generally prevents its use as an injectable material. Modified bioactive alginate hydrogels have demonstrated potential both as cell carriers in neurotransplantation and as scaffolds for the regeneration of myelinated and nonmyelinated axons across spinal cord gaps (Kataoka et al., 2004; Novikova et al., 2006; Tobias et al., 2005). Agarose is a natural colloid extracted from seaweed and is composed of an alternating copolymer of linear 1,4-linked 3,6anhydro- $\alpha$-L-galactopyranose and 1,3-linked- $\beta$-D-galactopyranose. Agarose hydrogels require large temperature changes to induce gelation and have mostly been used as preformed scaffolds (Stokols and Tuszynski, 2006; Stokols et al., 2006). However, in situ gelation has been accomplished through the use of a localized cooling system during implantation (Jain et al., 2006). Modified, bioactive agarose gels have been shown to support the growth of dorsal root ganglia and to promote cellular regeneration in rat spinal cords (Balgude et al., 2001; Jain et al., 2006; Stokols et al., 2006).

Some examples of injectable hydrogel scaffolds include Matrigel, collagen, and chitosan formulations. Matrigel is a thermosensitive, injectable material extensively used in vitro as a control hydrogel material to study the proliferation and differentiation of many cell types (Novikova et al., 2006; Tsai et al., 2006; X.M. Xu et al., 1999). It consists of a solubilized basement membrane preparation extracted from the Engelbreth-Holm-Swarm (EHS) mouse sarcoma, a tumor rich in ECM proteins. Even though Matrigel is easily obtained and extensively used for in vitro and in vivo studies, its preparation from mouse tumor cells makes it an unlikely candidate for transplantation in humans. The relatively unknown composition of Matrigel makes application of experimental results to other systems quite difficult, but does promote the strategy of a heterogeneous hydrogel composition for cell growth and differentiation.

Collagen hydrogels can be prepared using either covalent chemical crosslinkers (discussed in the section "Covalently Crosslinked Materials") or physical fibrillogenesis. Scaffoldfabrication procedures employing fibrillogenesis allow collagen to be used as an injectable material and trigger gel formation by adjusting a cold, acid-solubilized collagen mixture to physiological $\mathrm{pH}$ and temperature (Grillo and Gross, 1962). Physical collagen hydrogels have been widely studied and have demonstrated a high level of cell compatibility (Orwin and Hubel, 2000; Wakitani et al., 1998).

Similar to collagen, chitosan-based hydrogels can be prepared using either covalent (discussed in the section "Covalently Crosslinked Materials") or physical interactions. Injectable, physically crosslinked chitosan-based scaffolds that gel in response to thermal shifts have been prepared using two main approaches. The first approach has involved grafting thermosensitive polymers such as poly ( $N$-isopropylacrylamide) onto chitosan chains to trigger temperature induced gelation (Bhattarai et al., 2005; Cho et al., 2004). The other approach uses the addition of glycerophosphate salt to dissolve otherwise insoluble chitosan polymers at low temperatures in a $\mathrm{pH}$ neutral solution that forms a gel when exposed to higher temperatures (Crompton et al., 2006).

One of the most recent developments in injectable CNS scaffold design has been synthetic peptide/protein-based hydrogels, which include self-assembling peptides, peptide amphiphiles, and physical protein hydrogels. Unlike natu- 
rally derived materials, these engineered peptides can be easily manufactured in large-scale quantities, produced with consistent quality control, and sterilized through simple ultraviolet radiation or filtration. Self-assembling peptides are composed of short, repeating units of amino acids that form nanofibrous scaffolds in response to thermal changes or elevations in salt concentration resulting from the addition of cell culture media or in vivo injection. These self-assembling peptide hydrogel scaffolds have a defined composition and have been used successfully as synthetic cell scaffolds for in vitro and in vivo culture of neuronal cells; one of them is currently commercialized as PuraMatrix ${ }^{\mathrm{TM}}$ (3DM, Inc., Cambridge, MA) (Semino et al., 2004; S.G. Zhang, 2003).

Peptide amphiphiles are bimodular molecules consisting of hydrophilic peptide heads and hydrophobic alkyl tails that self-assemble into weak, nanofibrous hydrogels. Self-assembly of peptide amphiphiles is induced through changes in $\mathrm{pH}$ or the introduction of ionic gradients; these environmental triggers have been tuned to match a transition into physiological conditions. While these scaffolds generally are not inherently cell adhesive, a variety of ECM peptides can be easily incorporated into the hydrophilic peptide head to elicit specific cell interactions (Tysseling-Mattiace et al., 2008). With incorporation of the IKVAV sequence, self-assembling nanofiber gels have been recently shown to inhibit glial scar formation, promote axon elongation, and to result in behavioral improvements after spinal cord injury in mice models, as well as to enhance differentiation of neural progenitor cells (Silva et al., 2004; Tysseling-Mattiace et al., 2008).

In addition to small peptides and peptide amphiphiles, full proteins can be designed to heteroassemble into weak hydrogels. Using a molecular-recognition strategy, two separate protein components can bind together through stoichiometric hydrogen-bonding to form a physical hydrogel. This heteroassembly gelation strategy offers a unique advantage because cells are not exposed to any environmental changes during encapsulation and can be kept at constant, ideal physiological conditions (Wong Po Foo and Heilshorn, 2007). These materials have not yet been tested in vivo for their regenerative capacity, but initial in vitro cell studies have indicated good biocompatibility with neural progenitor cells.

\section{Critical design parameters}

Mechanical strength and degradability. As previously mentioned, the choice between covalent and physical crosslinking can have direct implications on the mechanical strength of a hydrogel scaffold. Covalent crosslinking techniques often offer more tunability and typically result in more rigid materials, while physical crosslinking methods usually result in more compliant materials. The initial mechanical strength of a hydrogel and the change in mechanical properties over time due to degradation are thought to be integral to the success of a regenerative scaffold. It is hypothesized that matching the mechanical properties of a material to the surrounding native tissue more closely mimics the natural cellular environment and may facilitate cell migration across the tissue-implant boundary (Woerly et al., 2004; X.J. Yu and Bellamkonda, 2001). Also, recent experimental evidence has indicated that the mechanical strength of a material can affect cell growth and differentiation, with the optimal material elastic modulus matching that of the native growth environ- ment (Balgude et al., 2001; Flanagan et al., 2002; Leach et al., 2007; Saha et al., 2008). There is some disagreement in the literature on the exact elastic modulus range of CNS tissue, but the values are typically reported within the range of $\sim 3 \mathrm{kPa}$ to $300 \mathrm{kPa}$ for spinal cord tissue (Oakland et al., 2006; Ozawa et al., 2001) and $~ 500 \mathrm{~Pa}$ for brain tissue (Saha et al., 2008). The soft nature of CNS tissue potentially makes the highly swollen and weak nature of hydrogels ideal for use in this environment.

Furthermore, it is conjectured that the mechanical properties of a material must respond to the formation of new tissue. It is thought that if a material is too stiff (or densely packed), cell proliferation and neuronal extension may be inhibited (Balgude et al., 2001). As a result, much attention has been focused on the development of biodegradable materials that aim to prevent a prolonged inflammatory response as well as limit obstruction, and promote nerve growth by allowing the material to be replaced by regenerating cells and their matrix. The two most prominent biodegradation strategies used in hydrogels are (i) uniform bulk degradation due to hydrolysis and (ii) proteolytic degradation of natural materials such as fibrin and chitosan by protease enzymes prevalent in the ECM or presented by growing cells (Freier et al., 2005b; Pittier et al., 2005). In addition to natural materials, recombinant proteins and synthetic polymers such as PEG and poly $(\mathrm{N}$ isopropylacrylamide-co-acrylic acid) have been specifically designed to degrade in response to ECM proteases (Kim et al., 2005; Mahoney and Anseth, 2006; Rizzi et al., 2006; Straley and Heilshorn, 2009; West and Hubbell, 1999). Outgrowth of neuronal processes has been shown to be enhanced by PEGPLA scaffolds that degrade by hydrolysis with faster degradation kinetics and by fibrin matrices degraded by enzymatic serine proteases (Mahoney and Anseth, 2006; Rizzi et al., 2006). Much quantitative work still needs to be done in creating an appropriate balance between the initial material mechanical properties, the material degradation rate, and the cellular regeneration rate.

Cell adhesion. In order to effectively promote regeneration, a hydrogel scaffold must first support cell attachment. Cell adhesivity is perhaps even more important for hydrogel design than guidance channel design, due to the higher degree of integration between the scaffold matrix and cells. Since hydrogels ultimately present a three-dimensional surface for in vivo regeneration, it is important that in vitro material optimization studies be conducted in a simulated threedimensional environment rather than the more traditional two-dimensional approach. Most natural and synthetic materials used to fabricate hydrogels are not cell adhesive, so it has become common to crosslink full-length ECM proteins or functional peptide sequences to the original hydrogel to increase cell attachment (Cui et al., 2006; Tysseling-Mattiace et al., 2008; L.M.Y. Yu et al., 2007). For example, HA scaffolds were shown to require modification with the RGD peptide in order to support brain regeneration in rats (Cui et al., 2006). Also, fibrin gels modified with laminin and $N$-cadherin peptides have demonstrated an enhancement in neurite extension of up to $\sim 75 \%$ in vitro (Schense et al., 2000). More recent materials such as dextran, which support poor cell growth alone, have shown much more promise as tissue engineering scaffolds once modified with commonly studied peptides (Levesque and Shoichet, 2006). Important considerations in 
the attachment of ECM domains to scaffolds are the ligand of choice and the density of the ligand. In the culture of neural stem cells, a minimum RGD density was found to be necessary to promote growth (Saha et al., 2007). Also, peptide amphiphiles that amplify IKVAV peptide presentation by a factor of $10^{3}$ relative to laminin have shown increased regenerative capacity when compared to laminin in the mouse spinal cord (Tysseling-Mattiace et al., 2008). Current studies are being conducted to optimize peptide concentrations and to identify new cell-adhesive peptide sequences, especially for applications involving cell delivery.

Cell encapsulation and transplantation. A major driving force for the use of hydrogels in CNS regeneration is their potential as delivery platforms for cells. Due to the inhibitory repair environment found at spinal cord injury sites, the use of hydrogels in combination with cells may promote functional recovery. Transplantation of cells with hydrogel scaffolds requires careful optimization of the hydrogel microenvironment, including cell receptor and ligand densities, mechanical properties, and growth-factor incorporation to stimulate cell differentiation and proliferation. The inherent sensitivity of cells places limits on material selection, since some environmental triggers and chemical crosslinkers used to form hydrogel networks may harm cell viability. The primary cells of interest for delivery in spinal cord scaffolds are neural progenitor cells, Schwann cells, and olfactoryensheathing glia. Neural progenitor cells have been found in the adult brain and spinal cord, are self-renewing, and give rise to progenies that can differentiate into neurons, astrocytes, and oligodendrocytes (Lois and Alvarezbuylla, 1993; Reynolds and Weiss, 1992). Some success has been achieved using synthetic hydrogels in combination with neural progenitor cells for the formation of neo-tissue (Nomura et al., 2008b; Teng et al., 2002).

Schwann cells, a type of neuroglia found in the PNS, have been shown to play a crucial role in the development and regeneration of peripheral axons. The main function of Schwann cells is to wrap axons within a myelin-insulating sheath. However, when a peripheral nerve is damaged, they assist in removal of debris, produce trophic factors, secrete ECM components, and remyelinate regenerated axons. Schwann cells have been shown to migrate into CNS injury sites, and it is hypothesized that direct transplantation into the CNS may aid in regeneration. Most in vivo work has used nerve guidance tubes for the delivery of these cells. Both semipermeable PAN/PVC channels filled with Schwann cells suspended in Matrigel and Schwann cells wrapped with PHB have shown partial regeneration in rat spinal cord injuries but resulted in limited functional recovery (Fouad et al., 2005; Novikova et al., 2008).

Olfactory ensheathing glia (OEG) are found within the olfactory bulb and provide protection to olfactory axons, allowing them to regenerate in adults and establish contacts with their targets. OEGs have shown promise in overcoming the inhibitory spinal cord environment faced by regenerating axons, primarily through studies involving nerve guidance channels. Transplantation of OEGs was shown to promote regeneration of dorsal root axons into the spinal cords of rats and led to increased axonal growth across transected rat spinal cords (Bunge, 2002; Fouad et al., 2005). Much work still needs to be done to provide permissive microenvironments for the delivery of neural progenitor cells, Schwann cells, and OEGs using hydrogels. However, the positive results seen to date using scaffolds and nerve guidance channels provide motivation for this work, and the flexible and injectable nature of some hydrogel scaffolds makes them an attractive delivery platform.

Biomolecule delivery. Along with delivery of exogenous cells, various biomolecules may also be encapsulated within a hydrogel to provide a more permissive environment. The use of hydrogels to deliver biomolecules alone may provide an environment that more effectively encourages regeneration of endogenous cells. Two important classes of biomolecules that have been identified for their promise in promoting nerve regeneration are neurotrophic factors and antagonists for neurite growth inhibitors.

Neurotrophic factors play an important role in promoting neuronal survival and neurite outgrowth, and are therefore considered promising candidates for stimulating and directing the growth of regenerating nerve fibers. The main motivation behind using hydrogels to deliver exogenous neurotrophic factors is that direct-injection methods fail to localize these molecules at the injury site and the molecules may quickly degrade after injection (Blesch and Tuszynski, 2007). Hydrogel scaffolds are being designed to deliver neurotrophic factors in a spatially and temporally controlled fashion. Strategies developed for growth-factor delivery have included coupling molecules to polymer matrices for cellinduced release (Taylor et al., 2006), encapsulation of growthfactor secreting cells (Tobias et al., 2005), gene delivery (review article: Tuszynski, 1997), and controlled release from polymeric microparticles (Jain et al., 2006). The in vivo application of some of these strategies demonstrated enhanced cell survival and outgrowth of spinal cord neurons. For example, the addition of brain-derived neurotrophic factor (BDNF) to agarose matrices and the encapsulation of BDNF-producing fibroblasts within alignate matrices have resulted in enhanced regeneration of neurons and some functional recovery in rat spinal cord injuries (Jain et al., 2006; Tobias et al., 2005). In addition to promoting cell growth, the presentation of neurotrophic factors in gradients within scaffolds has been studied for guidance of regenerating neurons. The idea is to mimic the neuronal development process during which growth factors are present in gradients to guide growing axons to their intended targets. Several in vitro studies have demonstrated that neuronal cells are guided by immobilized gradients in scaffolds (Dodla and Bellamkonda, 2008; Moore et al., 2006; Musoke-Zawedde and Shoichet, 2006). The presence of laminin and NGF gradients in agarose scaffolds has also shown better functional recovery of long peripheral nerve gaps than uniform concentration scaffolds (Dodla and Bellamkonda, 2008).

While the delivery of neurotrophic factors attempts to directly promote nerve regeneration through stimulation of neurite elongation, a complementary strategy is the delivery of factors aimed at limiting the formation of the glial scar and/ or blocking the effects of the glial scar. Glial scar formation is one of the biggest hurdles in CNS neuro-regeneration. It is thought that by either inhibiting or removing the factors inherent to glial scar formation, nerve regrowth could be facilitated. One main reason for poor regeneration in the CNS is the production of molecules in myelin that suppress neurite 
outgrowth; these molecules include neurite outgrowth inhibitor (Nogo), myelin-associated glycoprotein (MAG), and chondroitin sulfate (Chen et al., 2000a; GrandPre et al., 2000; Mukhopadhyay et al., 1994; Prinjha et al., 2000). Chrondroitin sulfate is an astrocyte-secreted proteoglycan that is upregulated after injury and has been extensively shown to suppress neurite regeneration. Enzymatic treatments have been successfully developed to mitigate the effects of this proteoglycan (Hynds and Snow, 1999; Lin et al., 2008).

Hydrogels have the potential to aid in the delivery of inhibitory molecules as with neurotrophic factors; however, much work still needs to be done. Some preliminary success has been seen in vitro and in vivo with HA hydrogels combined with a Nogo-66 receptor antagonist (Hou et al., 2006; Ma et al., 2007). Also, the development of a Nogo-66 antagonist peptide NEP1-40 presents an opportunity for hydrogel delivery through peptide linkage to the polymer backbone (GrandPre et al., 2002). Ultimately, a highly integrated scaffold that delivers a combination of growth factors, antagonists for neurite growth inhibitors, or other biomolecules may prove more successful, since the delivery of single molecules has yet to demonstrate full functional recovery following CNS injury.

Scaffold topography and microstructure. Another strategy in neural regeneration is controlling topographic properties of materials both to guide and enhance neurite outgrowth. Attempts are being made to more closely mimic the in vivo ECM environment by spatially patterning biochemical cues and introducing channels or fibers that mediate contact guidance for directed neurite outgrowth. Several in vitro experiments have demonstrated that patterned surfaces of adhesive (full proteins or peptides) and nonadhesive regions exhibit highly selective neuronal attachment and outgrowth on the adhesive regions (Z.P. Zhang et al., 2005). These promising results have inspired the development of techniques for three-dimensional patterning of biochemical cues into hydrogel scaffolds (Wosnick and Shoichet, 2008; Wylie and Shoichet, 2008). In addition, micropatterned materials fabricated using soft- and photo-lithography techniques have shown that the presence of microchannels affects the direction of neurite outgrowth, number of neurites, and length of neurites, and that neuronal cells may prefer to grow on ridges of channels rather than in grooves (Johansson et al., 2006; Mahoney et al., 2005; S. Wang et al., 2009). Knowledge of the beneficial effects imparted by microchannels on neurite guidance has inspired the fabrication of hydrogel scaffolds containing uniaxial pores, but in vivo work still needs to be done to determine the efficacy of this approach (Flynn et al., 2003; Stokols and Tuszynski, 2006). While both patterned channels and biochemical cues have shown promise alone, many experiments have shown that simultaneous optimization of these properties may result in synergistic effects (Gomez et al., 2007; Li and Folch, 2005). Similar to microchannels, individual fibers and aligned fibrous scaffolds have also demonstrated directional neuronal growth (Sell et al., 2007). In direct comparisons between aligned and unaligned poly-Llactate fibrous scaffolds, both neural progenitor cells and dorsal root ganglia have been shown to grow parallel to aligned fibers (Corey et al., 2007; F. Yang et al., 2005). A relatively new approach involving the integration of fibers within hydrogel materials to provide a three-dimensional array of fibers for neuronal guidance within a growth-promoting environment is beginning to gain appeal (Newman et al., 2006; Novikova et al., 2008).

\section{Conclusions and Future Perspective}

Overall, there has been significant work completed in the development of guidance channels and hydrogel scaffolds for nerve-regeneration applications. The results of this work have seen success in the design of nerve guidance channels for the treatment of short nerve gaps in the PNS. However, there has yet to emerge a dominant material or design strategy capable of promoting functional recovery following traumatic spinal cord injury. The naturally inhibitory environment found in CNS injury sites presents a difficult problem for the field of tissue engineering. It is now believed that a highly integrated approach that attempts to mimic the permissive ECM environment seen during development may have the most potential for success. This approach is thought to likely involve the design and implantation of a growth-promoting scaffold/ channel that optimizes multiple material properties such as mechanical strength, cell-adhesivity, biomolecule delivery, cell transplantation, electrical activity, degradability, and topography.

Up to this point, most scaffolds and channels have only addressed one or two key design properties resulting in the promotion of enhanced neurite elongation in vitro and in vivo but limited functional recovery in vivo. Recently, more implant designs are beginning to focus on multiple material design properties with the hope that this will more effectively achieve functional regeneration (Saha et al., 2007; Straley and Heilshorn, 2009). However, with the fabrication of such complex materials, communication between biomaterial designers, neurobiologists, and surgeons is becoming increasingly important. Such communication will help to ensure that new materials are able to be effectively implanted into the injury site and that they incorporate the most relevant biological cues to initiate regeneration. The recent trend in synthesis of injectable hydrogels is a good example of this communication. Injectable hydrogels provide a much simpler implantation strategy, which may be necessary for the complex geometries and partial nerve transections often encountered in spinal cord injuries.

Optimization of such a large number of design parameters and the large variety of materials currently being studied makes progress difficult. To expedite this process, recent work has involved the development of approaches to systematically compare already developed materials (Sun et al., 2008). More work similar to this would be highly valuable to the field of CNS tissue regeneration and would help to accelerate progress. Before implantation into animal models, most materials undergo significant in vitro testing to determine biocompatibility and regenerative capacity. There has recently been a push to use three-dimensional cell studies over twodimensional experiments, since they more accurately mimic the in vivo environment. Results emphasizing the importance of such factors as mechanical strength (Balgude et al., 2001; Flanagan et al., 2002; Leach et al., 2007; Saha et al., 2008) support this trend and encourage more widespread application of three-dimensional in vitro cell studies to limit time spent on screening new material designs. In addition, a more standardized system for in vivo testing of material efficacy 
may help in direct comparison of materials detailed in the literature. Currently, spinal cord injury animal models involve compression (Gruner, 1992; Rivlin and Tator, 1978), partial transection (Blesch and Tuszynski, 2003), or complete transection (Ramon-Cueto and Nietosampedro, 1994) using animals with a wide variation of species, size, age, sex, and body weight, making it difficult to compare different repair strategies and biomaterial designs. Complete transection models are the most widely used and produce the most reproducible results but do not effectively mimic human CNS injury. Use of such models may help initially to test new materials, but could lead to the design of materials that are difficult to surgically implant in more realistic injury sites, and may downplay the effectiveness of some materials due to the severity of the injury model.

Recent developments in biomaterial design are encouraging, but new materials that provide tunable platforms that address multiple key scaffold design criteria are currently needed. Progress toward the design and optimization of such scaffolds may potentially be hastened through more collaboration, better in vitro three-dimensional models, and more standardized in vivo animal models.

\section{Author Disclosure Statement}

No competing financial interests exist.

\section{References}

Ahmed, M.R., and Jayakumar, R. (2003). Peripheral nerve regeneration in RGD peptide incorporated collagen tubes. Brain Res. 993, 208-216.

Ao, Q., Wang, A.J., Cao, W.L., Zhang, L., Kong, L.J., He, Q., Gong, Y.D., and Zhang, X.F. (2006). Manufacture of multimicrotubule chitosan nerve conduits with novel molds and characterization in vitro. J. Biomed. Mater. Res. 77A, 11-18.

Avellino, A.M., Hart, D., Dailey, A.T., Mackinnon, M., Ellegala, D., and Kliot, M. (1995). Differential macrophage responses in the peripheral and central nervous system during wallerian degeneration of axons. Exp. Neurol. 136, 183-198.

Bakshi, A., Fisher, O., Dagci, T., Himes, B.T., Fischer, I., and Lowman, A. (2004). Mechanically engineered hydrogel scaffolds for axonal growth and angiogenesis after transplantation in spinal cord injury. J. Neurosurg. Spine 1, 322-329.

Balgude, A.P., Yu, X., Szymanski, A., and Bellamkonda, R.V. (2001). Agarose gel stiffness determines rate of DRG neurite extension in 3D cultures. Biomaterials 22, 1077-1084.

Bamber, N.I., Li, H., Lu, X., Oudega, M., Aebischer, P., and Xu, X.M. (2001). Neurotrophins BDNF and NT-3 promote axonal reentry into the distal host spinal cord through Schwann cellseeded mini-channels. Eur. J. Neurosci. 13, 257-268.

Belkas, J.S., Munro, C.A., Shoichet, M.S., Johnston, M., and Midha, R. (2005). Long-term in vivo biomechanical properties and biocompatibility of poly(2-hydroxyethyl methacrylate-co-methyl methacrylate) nerve conduits. Biomaterials 26, 1741-1749.

Benowitz, L., and Yin, Y.Q. (2008). Rewiring the injured CNS: Lessons from the optic nerve. Exp. Neurol. 209, 389-398.

Berger, A., and Mailander, P. (1991). Advances in peripheral nerve repair in emergency surgery of the hand. World J. Surg. 15, 493-500.

Bhatheja, K., and Field, J. (2006). Schwann cells: Origins and role in axonal maintenance and regeneration. Int. J. Biochem. Cell Biol. 38, 1995-1999.
Bhattarai, N., Ramay, H.R., Gunn, J., Matsen, F.A., and Zhang, M.Q. (2005). PEG-grafted chitosan as an injectable thermosensitive hydrogel for sustained protein release. J. Control. Release 103, 609-624.

Bjugstad, K.B., Redmond, D.E., Lampe, K.J., Kern, D.S., Sladek, J.R., and Mahoney, M.J. (2008). Biocompatibility of PEG-based hydrogels in primate brain. Cell Transplant. 17, 409-415.

Blesch, A., and Tuszynski, M.H. (2003). Cellular GDNF delivery promotes growth of motor and dorsal column sensory axons after partial and complete spinal cord transections and induces remyelination. J. Comp. Neurol. 467, 403-417.

Blesch, A., and Tuszynski, M.H. (2007). Transient growth factor delivery sustains regenerated axons after spinal cord injury. J. Neurosci. 27, 10535-10545.

Bloch, J., Fine, E.G., Bouche, N., Zurn, A.D., and Aebischer, P. (2001). Nerve growth factor and neurotrophin-3 releasing guidance channels promote regeneration of the transected rat dorsal root. Exp. Neurol. 172, 425-432.

Borgens, R.B., Roederer, E., and Cohen, M.J. (1981). Enhanced spinal cord regeneration in lamprey by applied electric fields. Science 213, 611-617.

Borgens, R.B., Shi, R.Y., and Bohnert, D. (2002). Behavioral recovery from spinal cord injury following delayed application of polyethylene glycol. J. Exp. Biol. 205, 1-12.

Bracken, M.B., Shepard, M.J., Collins, W.F., Holford, T.R., Young, W., Baskin, D.S., Eisenberg, H.M., Flamm, E., Leosummers, L., Maroon, J., Marshall, L.F., Perot, P.L., Piepmeier, J., Sonntag, V.K.H., Wagner, F.C., Wilberger, J.E., and Winn, H.R. (1990). A randomized, controlled trial of methylpredisolone or naloxine in the treatment of acute spinal cord injury - Results of the 2nd National Acute Spinal Cord Injury Study. New Engl. J. Med. 322, 1405-1411.

Bunge, M.B. (2002). Bridging the transected or contused adult rat spinal cord with Schwann cell and olfactory ensheathing glia transplants. Prog. Brain Res. 137, 275-282.

Busch, S.A., and Silver, J. (2007). The role of extracellular matrix in CNS regeneration. Curr. Opin. Neurobiol. 17, 120-127.

Ceballos, D., Navarro, X., Dubey, N., Wendelschafer-Crabb, G., Kennedy, W.R., and Tranquillo, R.T. (1999). Magnetically aligned collagen gel filling a collagen nerve guide improves peripheral nerve regeneration. Exp. Neurol. 158, 290-300.

Chen, M.S., Huber, A.B., van der Haar, M.E., Frank, M., Schnell, L., Spillmann, A.A., Christ, F., and Schwab, M.E. (2000a). Nogo$A$ is a myelin-associated neurite outgrowth inhibitor and an antigen for monoclonal antibody IN-1. Nature 403, 434-439.

Chen, Y.S., Hsieh, C.L., Tsai, C.C., Chen, T.H., Cheng, W.C., Hu, C.L., and Yao, C.H. (2000b). Peripheral nerve regeneration using silicone rubber chambers filled with collagen, laminin and fibronectin. Biomaterials 21, 1541-1547.

Cheng, M.Y., Gong, K., Li, J.M., Gong, Y.D., Zhao, N.M., and Zhang, X.F. (2004). Surface modification and characterization of chitosan film blended with poly-L-lysine. J. Biomater. Appl. 19, 59-75.

Cho, J.H., Kim, S.H., Park, K.D., Jung, M.C., Yang, W.I., Han, S.W., Noh, J.Y., and Lee, J.W. (2004). Chondrogenic differentiation of human mesenchymal stem cells using a thermosensitive poly( $N$-isopropylacrylamide) and water-soluble chitosan copolymer. Biomaterials 25, 5743-5751.

Collier, J.H., Camp, J.P., Hudson, T.W., and Schmidt, C.E. (2000). Synthesis and characterization of polypyrrole-hyaluronic acid composite biomaterials for tissue engineering applications. J. Biomed. Mater. Res. 50, 574-584.

Corey, J.M., Lin, D.Y., Mycek, K.B., Chen, Q., Samuel, S., Feldman, E.L., and Martin, D.C. (2007). Aligned electrospun 
nanofibers specify the direction of dorsal root ganglia neurite growth. J. Biomed. Mater. Res. 83A, 636-645.

Crompton, K.E., Tomas, D., Finkelstein, D.I., Marr, M., Forsythe, J.S., and Horne, M.K. (2006). Inflammatory response on injection of chitosan/GP to the brain. J. Mater. Sci. Mater. Med. $17,633-639$.

'Cui, F.Z., Tian, W.M., Hou, S.P., Xu, Q.Y., and Lee, I.S. (2006). Hyaluronic acid hydrogel immobilized with RGD peptides for brain tissue engineering. J. Mater. Sci. Mater. Med. 17, 1393-1401.

Curtis, A., and Wilkinson, C. (1997). Topographical control of cells. Biomaterials 18, 1573-1583.

Dalton, P.D., Flynn, L., and Shoichet, M.S. (2002). Manufacture of poly(2-hydroxyethyl methacrylate-co-methyl methacrylate) hydrogel tubes for use as nerve guidance channels. Biomaterials 23, 3843-3851.

Danielsen, N., Dahlin, L.B., and Thomsen, P. (1993). Inflammatory cells and mediators in the silicone chamber model for nerve regeneration. Biomaterials 14, 1180-1185.

De Laporte, L., and Shea, L.D. (2007). Matrices and scaffolds for DNA delivery in tissue engineering. Adv. Drug Deliv. Rev. 59, 292-307.

Dodla, M.C., and Bellamkonda, R.V. (2008). Differences between the effect of anisotropic and isotropic laminin and nerve growth factor presenting scaffolds on nerve regeneration across long peripheral nerve gaps. Biomaterials 29, 33-46.

Fine, E.G., Valentini, R.F., Bellamkonda, R., and Aebischer, P. (1991). Improved nerve regeneration through piezoelectric vinylidene fluoride-trivfluoroethylene copolymer guidance channels. Biomaterials 12, 775-780.

Flanagan, L.A., Ju, Y.E., Marg, B., Osterfield, M., and Janmey, P.A. (2002). Neurite branching on deformable substrates. Neuroreport 13, 2411-2415.

Flynn, L., Dalton, P.D., and Shoichet, M.S. (2003). Fiber templating of poly(2-hydroxyethyl methacrylate) for neural tissue engineering. Biomaterials 24, 4265-4272.

Fouad, K., Schnell, L., Bunge, M.B., Schwab, M.E., Liebscher, T., and Pearse, D.D. (2005). Combining Schwann cell bridges and olfactory-ensheathing glia grafts with chondroitinase promotes locomotor recovery after complete transection of the spinal cord. J. Neurosci. 25, 1169-1178.

Freier, T., Montenegro, R., Koh, H.S., and Shoichet, M.S. (2005a). Chitin-based tubes for tissue engineering in the nervous system. Biomaterials 26, 4624-4632.

Freier, T., Koh, H.S., Kazazian, K., and Shoichet, M.S. (2005b). Controlling cell adhesion and degradation of chitosan films by $\mathrm{N}$-acetylation. Biomaterials 26, 5872-5878.

Frostick, S.P., Yin, Q., and Kemp, G.J. (1998). Schwann cells, neurotrophic factors, and peripheral nerve regeneration. Microsurgery 18, 397-405.

Gautier, S.E., Oudega, M., Fragoso, M., Chapon, P., Plant, G.W., Bunge, M.B., and Parel, J.M. (1998). Poly( $\alpha$-hydroxyacids) for application in the spinal cord: Resorbability and biocompatibility with adult rat Schwann cells and spinal cord. J. Biomed. Mater. Res. 42, 642-654.

Gomez, N., Lu, Y., Chen, S.C., and Schmidt, C.E. (2007). Immobilized nerve growth factor and microtopography have distinct effects on polarization versus axon elongation in hippocampal cells in culture. Biomaterials 28, 271-284.

GrandPre, T., Li, S.X., and Strittmatter, S.M. (2002). Nogo-66 receptor antagonist peptide promotes axonal regeneration. Nature 417, 547-551.

GrandPre, T., Nakamura, F., Vartanian, T., and Strittmatter, S.M. (2000). Identification of the Nogo inhibitor of axon regeneration as a reticulon protein. Nature 403, 439-444.
Greenwald, S.E., and Berry, C.L. (2000). Improving vascular grafts: The importance of mechanical and haemodynamic properties. J. Pathol. 190, 292-299.

Grillo, H.C., and Gross, J. (1962). Thermal reconstitution of collagen from solution and the response to its heterologous implantation. J. Surg. Res. 2, 69-82.

Gruner, J.A. (1992). A monitored contusion model of spinal cord injury in the rat. J. Neurotrauma 9, 123-128.

Gupta, D., Tator, C.H., and Shoichet, M.S. (2006). Fast-gelling injectable blend of hyaluronan and methylcellulose for intrathecal, localized delivery to the injured spinal cord. Biomaterials 27, 2370-2379.

Haipeng, G., Yinghui, Z., Jianchun, L., Yandao, G., Nanming, Z., and Xiufang, Z. (2000). Studies on nerve cell affinity of chitosan-derived materials. J. Biomed. Mater. Res. 52, 285-295.

Hejcl, A., Urdzikova, L., Sedy, J., Lesny, P., Pradny, M., Michalek, J., Burian, M., Hajek, M., Zamecnik, J., Jendelova, P., and Sykova, E. (2008). Acute and delayed implantation of positively charged 2-hydroxyethyl methacrylate scaffolds in spinal cord injury in the rat. J. Neurosurg. Spine 8, 67-73.

Hiemstra, C., van der Aa, L.J., Zhong, Z.Y., Dijkstra, P.J., and Feijen, J. (2007). Rapidly in situ-forming degradable hydrogels from dextran thiols through michael addition. Biomacromolecules 8, 1548-1556.

Hou, S., Tian, W., Xu, Q., Cui, F., Zhang, J., Lu, Q., and Zhao, C. (2006). The enhancement of cell adherence and inducement of neurite outgrowth of dorsal root ganglia co-cultured with hyaluronic acid hydrogels modified with Nogo-66 receptor antagonist in vitro. Neuroscience 137, 519-529.

Huang, Y.-C., and Huang, Y.-Y. (2006). Biomaterials and strategies for nerve regeneration. Artificial Organs 30, 514-522.

Hudson, T.W., Zawko, S., Deister, C., Lundy, S., Hu, C.Y., Lee, K., and Schmidt, C.E. (2004). Optimized acellular nerve graft is immunologically tolerated and supports regeneration. Tissue Eng. 10, 1641-1651.

Hynds, D.L., and Snow, D.M. (1999). Neurite outgrowth inhibition by chondroitin sulfate proteoglycan: Stalling/stopping exceeds turning in human neuroblastoma growth cones. Exper. Neurol. 160, 244-255.

Ijkema-Paassen, J., Jansen, K., Gramsbergen, A., and Meek, M.F. (2004). Transection of peripheral nerves, bridging strategies and effect evaluation. Biomaterials 25, 1583-1592.

Itoh, S., Takakuda, K., Kawabata, S., Aso, Y., Kasai, K., Itoh, H., and Shinomiya, K. (2002). Evaluation of cross-linking procedures of collagen tubes used in peripheral nerve repair. Biomaterials 23, 4475-4481.

Jain, A., Kim, Y.T., McKeon, R.J., and Bellamkonda, R.V. (2006). In situ gelling hydrogels for conformal repair of spinal cord defects, and local delivery of BDNF after spinal cord injury. Biomaterials 27, 497-504.

Johansson, F., Carlberg, P., Danielsen, N., Montelius, L., and Kanje, M. (2006). Axonal outgrowth on nano-imprinted patterns. Biomaterials 27, 1251-1258.

Joosten, E.A.J., Bar, P.R., and Gispen, W.H. (1995). Collagen implants and corticospinal axonal growth after mid-thoracic spinal cord lesion in the adult rat. J. Neurosci. Res. 41, 481490.

Ju, Y.E., Janmey, P.A., McCormick, M.E., Sawyer, E.S., and Flanagan, L.A. (2007). Enhanced neurite growth from mammalian neurons in three-dimensional salmon fibrin gels. Biomaterials 28, 2097-2108.

Kassar-Duchossoy, L., Duchossoy, Y., Rhrich-Haddout, F., and Horvat, J.C. (2001). Reinnervation of a denervated skeletal muscle by spinal axons regenerating through a collagen 
channel directly implanted into the rat spinal cord. Brain Res. 908, 25-34.

Kataoka, K., Suzuki, Y., Kitada, M., Hashimoto, T., Chou, H., Bai, H.L., Ohta, M., Wu, S., Suzuki, K., and Ide, C. (2004). Alginate enhances elongation of early regenerating axons in spinal cord of young rats. Tissue Eng. 10, 493-504.

Katayama, Y., Montenegro, R., Freier, T., Midha, R., Belkas, J.S., and Shoichet, M.S. (2006). Coil-reinforced hydrogel tubes promote nerve regeneration equivalent to that of nerve autografts. Biomaterials 27, 505-518.

Kim, S., Chung, E.H., Gilbert, M., and Healy, K.E. (2005). Synthetic MMP-13 degradable ECMs based on poly $(N-$ isopropylacrylamide-co-acrylic acid) semi-interpenetrating polymer networks I: Degradation and cell migration. J. Biomed. Mater. Res. 75A, 73-88.

Kofuji, K.A., Oshirabe, H., Maeda, Y., Murata, Y., and Kawashima, S. (2003). Retention and release behavior of insulin in chitosan gel beads. J. Biomater. Sci. Polym. Ed. 14, 12431253.

Kotwal, A., and Schmidt, C.E. (2001). Electrical stimulation alters protein adsorption and nerve cell interactions with electrically conducting biomaterials. Biomaterials 22, 1055-1064.

Kretlow, J.D., Klouda, L., and Mikos, A.G. (2007). Injectable matrices and scaffolds for drug delivery in tissue engineering. Adv. Drug Delivery Rev. 59, 263-273.

Leach, J.B., and Schmidt, C.E. (2005). Characterization of protein release from photocrosslinkable hyaluronic acid-polyethylene glycol hydrogel tissue engineering scaffolds. Biomaterials 26, 125-135.

Leach, J.B., Brown, X.Q., Jacot, J.G., DiMilla, P.A., and Wong, J.Y. (2007). Neurite outgrowth and branching of PC12 cells on very soft substrates sharply decreases below a threshold of substrate rigidity. J. Neural Eng. 4, 26-34.

Levesque, S.G., and Shoichet, M.S. (2006). Synthesis of celladhesive dextran hydrogels and macroporous scaffolds. Biomaterials 27, 5277-5285.

Li, N.Z., and Folch, A. (2005). Integration of topographical and biochemical cues by axons during growth on microfabricated 3-D substrates. Exp. Cell Res. 311, 307-316.

Lin, R., Kwok, J.C.F., Crespo, D., and Fawcett, J.W. (2008). Chondroitinase $\mathrm{ABC}$ has a long-lasting effect on chondroitin sulphate glycosaminoglycan content in the injured rat brain. J. Neurochem. 104, 400-408.

Liu, S., Bodjarian, N., Langlois, O., Bonnard, A.S., Boisset, N., Peulve, P., Said, G., and Tadie, M. (1998). Axonal regrowth through a collagen guidance channel bridging spinal cord to the avulsed C6 roots: Functional recovery in primates with brachial plexus injury. J. Neurosci. Res. 51, 723734.

Ljungberg, C., Johansson-Ruden, G., Bostrom, K.J., Novikov, L., and Wiberg, M. (1999). Neuronal survival using a resorbable synthetic conduit as an alternative to primary nerve repair. Microsurgery 19, 259-264.

Lois, C., and Alvarezbuylla, A. (1993). Proliferating subventricular zone cells in the adult mammalian forebrain can differentiate into neurons and glia. Proc. Natl. Acad. Sci. USA 90, 2074-2077.

Longo, F.M., Skaper, S.D., Manthorpe, M., Williams, L.R., Lundborg, G., and Varon, S. (1983). Temporal changes of neuronotrophic activities accumulating in vivo within nerve regeneration chambers. Exp. Neurol. 81, 756-769.

Lu, P., and Tuszynski, M.H. (2008). Growth factors and combinatorial therapies for CNS regeneration. Exp. Neurol. 209, 313-320.
Lundborg, G., Longo, F.M., and Varon, S. (1982). Nerve regeneration model and trophic factors in vivo. Brain Res. 232, 157161.

Luo, J., and Shi, R.Y. (2007). Polyethylene glycol inhibits apoptotic cell death following traumatic spinal cord injury. Brain Res. 1155, 10-16.

Ma, J., Tian, W.M., Hou, S.P., Xu, Q.Y., Spector, M., and Cui, F.Z. (2007). An experimental test of stroke recovery by implanting a hyaluronic acid hydrogel carrying a Nogo receptor antibody in a rat model. Biomed. Mater. 2, 233-240.

Mackinnon, S.E., and Hudson, A.R. (1992). Clinical application of peripheral nerve transplantation. Plast. Reconstr. Surg. 90, 695-699.

Mackinnon, S.E., Dellon, A.L., Hudson, A.R., and Hunter, D.A. (1984). Chronic nerve compression - An experimental model in the rat. Ann. Plast. Surg. 13, 112-120.

Mahoney, M.J., and Anseth, K.S. (2006). Three-dimensional growth and function of neural tissue in degradable polyethylene glycol hydrogels. Biomaterials 27, 2265-2274.

Mahoney, M.J., Chen, R.R., Tan, J., and Saltzman, W.M. (2005). The influence of microchannels on neurite growth and architecture. Biomaterials 26, 771-778.

Malafaya, P.B., Silva, G.A., and Reis, R.L. (2007). Natural-origin polymers as carriers and scaffolds for biomolecules and cell delivery in tissue engineering applications. Adv. Drug Delivery Rev. 59, 207-233.

Marmor, L. (1964). Regeneration of peripheral nerves by irradiated homografts. J. Bone Joint Surg. Am. 46, 383-394.

Meiners, S., and Mercado, M.L.T. (2003). Functional peptide sequences derived from extracellular matrix glycoproteins and their receptors: Strategies to improve neuronal regeneration. Mol. Neurobiol. 27, 177-195.

Merle, M., Dellon, A.L., Campbell, J.N., and Chang, P.S. (1989). Complications from silicon polymer intubulation of nerves. Microsurgery 10, 130-133.

Millesi, H. (1981). Reappraisal of nerve repair. Surg. Clin. North Am. 61, 321-340.

Millesi, H., Berger, A., and Meissl, G. (1972). Interfascicular nerve grafting of median and ulnar nerves. J. Bone Joint Surg. Am. 54, 727-750.

Moon, L.D.F., Leasure, J.L., Gage, F.H., and Bunge, M.B. (2006). Motor enrichment sustains hindlimb movement recovered after spinal cord injury and glial transplantation. Restor. Neurol. Neurosci. 24, 147-161.

Moore, K., Macsween, M., and Shoichet, M. (2006). Immobilized concentration gradients of neurotrophic factors guide neurite outgrowth of primary neurons in macroporous scaffolds. Tissue Eng. 12, 267-278.

Moore, W.R., Graves, S.E., and Bain, G.I. (2001). Synthetic bone graft substitutes. Aust. N. Z. J. Surg. 71, 354-361.

Mukhopadhyay, G., Doherty, P., Walsh, F.S., Crocker, P.R., and Filbin, M.T. (1994). A novel role for myelin-assisted glycoprotein as an inhibitor of axonal regeneration. Neuron 13, 757767.

Musoke-Zawedde, P., and Shoichet, M.S. (2006). Anisotropic three-dimensional peptide channels guide neurite outgrowth within a biodegradable hydrogel matrix. Biomed. Mater. 1, 162-169.

Narotam, P.K., Jose, S., Nathoo, N., Taylon, C., and Vora, Y. (2004). Collagen matrix (DuraGen) in dural repair: Analysis of a new modified technique. Spine 29, 2861-2867.

National Spinal Cord Injury Statistical Center (2009). Spinal cord injury facts and figures at a glance. Available at http://www .fscip.org/facts.htm. Last accessed December 21, 2009. 
Newman, K.D., McLaughlin, C.R., Carlsson, D., Li, F., Liu, Y., and Griffith, M. (2006). Bioactive hydrogel-filament scaffolds for nerve repair and regeneration. Int. J. Artif. Organs 29, 1082-1091.

Nix, W.A., and Hopf, H.C. (1983). Electrical-stimulation of regenerating nerve and its effect on motor recovery. Brain Res. $272,21-25$.

Nomura, H., Tator, C.H., and Shoichet, M.S. (2006). Bioengineered strategies for spinal cord repair. J. Neurotrauma 23, 496-507.

Nomura, H., Baladie, B., Katayama, Y., Morshead, C.M., Shoichet, M.S., and Tator, C.H. (2008a). Delayed implantation of intramedullary chitosan channels containing nerve grafts promotes extensive axonal regeneration after spinal cord injury. Neurosurgery 63, 127-141.

Nomura, H., Zahir, T., Kim, H., Katayama, Y., Kulbatski, I., Morshead, C.M., Shoichet, M.S., and Tator, C.H. (2008b). Extramedullary chitosan channels promote survival of transplanted neural stem and progenitor cells and create a tissue bridge after complete spinal cord transection. Tissue Eng. 14, 649-665.

Novikova, L.N., Mosahebi, A., Wiberg, M., Terenghi, G., Kellerth, J.O., and Novikov, L.N. (2006). Alginate hydrogel and matrigel as potential cell carriers for neurotransplantation. J. Biomed. Mater. Res. 77A, 242-252.

Novikova, L.N., Pettersson, J., Brohlin, M., Wiberg, M., and Novikov, L.N. (2008). Biodegradable poly-beta-hydroxybutyrate scaffold seeded with Schwann cells to promote spinal cord repair. Biomaterials 29, 1198-1206.

Oakland, R.J., Hall, R.M., Wilcox, R.K., and Barton, D.C. (2006). The biomechanical response of spinal cord tissue to uniaxial loading. Proc. Inst. Mech. Eng. H 220, 489-492.

O Halloran, D.M., Russell, J.C., Griffin, M., and Pandit, A.S. (2006). Characterization of a microbial transglutaminase cross-linked type II collagen scaffold. Tissue Eng. 12, 14671474.

Ortiguela, M.E., Wood, M.B., and Cahill, D.R. (1987). Anatomy of the sural nerve complex. J. Hand Surg. Am. 12A, 1119-1123.

Orwin, E.J., and Hubel, A. (2000). In vitro culture characteristics of corneal epithelial, endothelial, and keratocyte cells in a native collagen matrix. Tissue Eng. 6, 307-319.

Oudega, M., Gautier, S.E., Chapon, P., Fragoso, M., Bates, M.L., Parel, J.M., and Bunge, M.B. (2001). Axonal regeneration into Schwann cell grafts within resorbable poly(alphahydroxyacid) guidance channels in the adult rat spinal cord. Biomaterials 22, 1125-1136.

Ozawa, H., Matsumoto, T., Ohashi, T., Sato, M., and Kokubun, S. (2001). Comparison of spinal cord gray matter and white matter softness: Measurement by pipette aspiration method. J. Neurosurg. 95, 221-224.

Park, T.G., Lu, W.Q., and Crotts, G. (1995). Importance of in vitro experimental conditions on protein release kinetics, stability and polymer degradation in protein encapsulated poly $(\mathrm{D}, \mathrm{L}-$ lactic acid-co-glycolic acid) microspheres. J. Control. Release 33, 211-222.

Patel, N., and Poo, M.M. (1982). Orientation of neurite growth by extracellular electric fields. J. Neurosci. 2, 483-496.

Petter-Puchner, A.H., Froetscher, W., Krametter-Froetscher, R., Lorinson, D., Redl, H., and van Griensven, M. (2007). The long-term neurocompatibility of human fibrin sealant and equine collagen as biomatrices in experimental spinal cord injury. Exp. Toxicol. Pathol. 58, 237-245.

Pitta, M.C., Wolford, L.M., Mehra, P., and Hopkin, J. (2001). Use of Gore-Tex tubing as a conduit for inferior alveolar and lin- gual nerve repair: Experience with 6 cases. J. Oral Maxillofac. Surg. 59, 493-496.

Pittier, R., Sauthier, F., Hubbell, J.A., and Hall, H. (2005). Neurite extension and in vitro myelination within three-dimensional modified fibrin matrices. J. Neurobiol. 63, 1-14.

Pogrel, M.A., McDonald, A.R., and Kaban, L.B. (1998). Gore-Tex tubing as a conduit for repair of lingual and inferior alveolar nerve continuity defects: A preliminary report. J. Oral Maxillofac. Surg. 56, 319-321.

Pollard, J.D., and Fitzpatrick, L. (1973). Ultrastructural comparison of peripheral nerve allografts and autografts. Acta Neuropathol. 23, 152-165.

Prinjha, R., Moore, S.E., Vinson, M., Blake, S., Morrow, R., Christie, G., Michlovich, D., Simmons, D.L., and Walsh, F.S. (2000). Neurobiology - Inhibitor of neurite outgrowth in humans. Nature 403, 383-384.

Ramon-Cueto, A., and Nietosampedro, M. (1994). Regeneration into the spinal cord of transected dorsal root axons is promoted by ensheathing glia transplants. Exp. Neurol. 127, 232244.

Reynolds, B.A., and Weiss, S. (1992). Generation of neurons and astrocytes from isolated cells of the adult mammalian central nervous system. Science 255, 1707-1710.

Richardson, P.M., McGuinness, U.M., and Aguayo, A.J. (1980). Axons from CNS neurons regenerate into PNS grafts. Nature 284, 264-265.

Rivers, T.J., Hudson, T.W., and Schmidt, C.E. (2002). Synthesis of a novel, biodegradable electrically conducting polymer for biomedical applications. Adv. Funct. Mater. 12, 33-37.

Rivlin, A.S., and Tator, C.H. (1978). Effect of duration of acute spinal cord compression in a new acute cord injury model in the rat. Surg. Neurol. 10, 38-43.

Rizzi, S.C., Ehrbar, M., Halstenberg, S., Raeber, G.P., Schmoekel, H.G., Hagenmuller, H., Muller, R., Weber, F.E., and Hubbell, J.A. (2006). Recombinant protein-co-PEG networks as celladhesive and proteolytically degradable hydrogel matrixes. Part II: Biofunctional characteristics. Biomacromolecules 7, 3019-3029.

Saha, K., Irwin, E.F., Kozhukh, J., Schaffer, D.V., and Healy, K.E. (2007). Biomimetic interfacial interpenetrating polymer networks control neural stem cell behavior. J. Biomed. Mater. Res. 81A, 240-249.

Saha, K., Keung, A., Irwin, E., Li, Y., Little, L., Schaffer, D., and Healy, K.E. (2008). Substrate modulus directs neural stem cell behavior. Biophys. J. 95, 4426-4438.

Schense, J.C., Bloch, J., Aebischer, P., and Hubbell, J.A. (2000). Enzymatic incorporation of bioactive peptides into fibrin matrices enhances neurite extension. Nature Biotechnol. 18, 415-419.

Schlosshauer, B., Dreesmann, L., Schaller, H.E., and Sinis, N. (2006). Synthetic nerve guide implants in humans: A comprehensive survey. Neurosurgery 59, 740-747.

Schmidt, C.E., and Leach, J.B. (2003). Neural tissue engineering: Strategies for repair and regeneration. Annu. Rev. Biomed. Eng. 5, 293-347.

Schmidt, C.E., Shastri, V.R., Vacanti, J.P., and Langer, R. (1997). Stimulation of neurite outgrowth using an electrically conducting polymer. Proc. Natl. Acad. Sci. USA 94, 8948-8953.

Seddon, H.J. (1963). Nerve grafting. J. Bone Joint Surg. Br. 45, 447-461.

Sell, S., Barnes, C., Smith, M., McClure, M., Madurantakam, P., Grant, J., McManus, M., and Bowlin, G. (2007). Extracellular matrix regenerated: Tissue engineering via electrospun biomimetic nanofibers. Polym. Int. 56, 1349-1360. 
Semino, C.E., Kasahara, J., Hayashi, Y., and Zhang, S.G. (2004). Entrapment of migrating hippocampal neural cells in threedimensional peptide nanofiber scaffold. Tissue Eng. 10, 643-655.

Shaw, D., and Shoichet, M.S. (2003). Toward spinal cord injury repair strategies: Peptide surface modification of expanded poly(tetrafluoroethylene) fibers for guided neurite outgrowth in vitro. J. Craniofac. Surg. 14, 308-316.

Silva, G.A., Czeisler, C., Niece, K.L., Beniash, E., Harrington, D.A., Kessler, J.A., and Stupp, S.I. (2004). Selective differentiation of neural progenitor cells by high-epitope density nanofibers. Science 303, 1352-1355.

Smetana, K., Sulc, J., Krcova, Z., and Pitrova, S. (1987). Intraocular biocompatibility of hydroxyethyl methacrylate and methacrylic acid copolymer partially hydrolyzed poly(2-hydroxyethyl methacrylate). J. Biomed. Mater. Res. 21, 1247-1253.

Stanec, S., and Stanec, Z. (1998a). Reconstruction of upperextremity peripheral-nerve injuries with ePTFE conduits. J. Reconstr. Microsurg. 14, 227-232.

Stanec, S., and Stanec, Z. (1998b). Ulnar nerve reconstruction with an expanded polytetrafluoroethylene conduit. Br. J. Plast. Surg. 51, 637-639.

Stokols, S., and Tuszynski, M.H. (2006). Freeze-dried agarose scaffolds with uniaxial channels stimulate and guide linear axonal growth following spinal cord injury. Biomaterials 27, 443-451.

Stokols, S., Sakamoto, J., Breckon, C., Holt, T., Weiss, J., and Tuszynski, M.H. (2006). Templated agarose scaffolds support linear axonal regeneration. Tissue Eng. 12, 2777-2787.

Straley, K., and Heilshorn, S.C. (2009). Independent tuning of multiple biomaterial properties using protein engineering. Soft Matter 5, 114-124.

Sun, T., Norton, D., Vickers, N., McArthur, S.L., Mac Neil, S., Ryan, A.J., and Haycock, J.W. (2008). Development of a bioreactor for evaluating novel nerve conduits. Biotechnol. Bioeng. 99, 1250-1260.

Suzuki, M., Itoh, S., Yamaguchi, I., Takakuda, K., Kobayashi, H., Shinomiya, K., and Tanaka, J. (2003). Tendon chitosan tubes covalently coupled with synthesized laminin peptides facilitate nerve regeneration in vivo. J. Neurosci. Res. 72, 646-659.

Taylor, S.J., and Sakiyama-Elbert, S.E. (2006). Effect of controlled delivery of neurotrophin-3 from fibrin on spinal cord injury in a long term model. J. Control. Release 116, 204-210.

Taylor, S.J., Rosenzweig, E.S., McDonald, J.W., and SakiyamaElbert, S.E. (2006). Delivery of neurotrophin-3 from fibrin enhances neuronal fiber sprouting after spinal cord injury. J. Control. Release 113, 226-235.

Teng, Y.D., Lavik, E.B., Qu, X.L., Park, K.I., Ourednik, J., Zurakowski, D., Langer, R., and Snyder, E.Y. (2002). Functional recovery following traumatic spinal cord injury mediated by a unique polymer scaffold seeded with neural stem cells. Proc. Natl. Acad. Sci. USA 99, 3024-3029.

Tobias, C.A., Han, S.S.W., Shumsky, J.S., Kim, D., Tumolo, M., Dhoot, N.O., Wheatley, M.A., Fischer, I., Tessler, A., and Murray, M. (2005). Alginate encapsulated BDNF-producing fibroblast grafts permit recovery of function after spinal cord injury in the absence of immune suppression. J. Neurotrauma 22, 138-156.

Tong, Y.W., and Shoichet, M.S. (2001). Enhancing the neuronal interaction on fluoropolymer surfaces with mixed peptides or spacer group linkers. Biomaterials 22, 1029-1034.

Tsai, E.C., Dalton, P.D., Shoichet, M.S., and Tator, C.H. (2004). Synthetic hydrogel guidance channels facilitate regeneration of adult rat brainstem motor axons after complete spinal cord transection. J. Neurotrauma 21, 789-804.
Tsai, E.C., Dalton, P.D., Shoichet, M.S., and Tator, C.H. (2006). Matrix inclusion within synthetic hydrogel guidance channels improves specific supraspinal and local axonal regeneration after complete spinal cord transection. Biomaterials 27, 519533.

Tuszynski, M.H. (1997). Gene therapy for nervous system disease. Front. Neurol. 835, 1-11.

Tysseling-Mattiace, V.M., Sahni, V., Niece, K.L., Birch, D., Czeisler, C., Fehlings, M.G., Stupp, S.I., and Kessler, J.A. (2008). Self-assembling nanofibers inhibit glial scar formation and promote axon elongation after spinal cord injury. J. Neurosci. 28, 3814-3823.

Valentini, R.F., Sabatini, A.M., Dario, P., and Aebischer, P. (1989). Polymer electret guidance channels enhance peripheral nerve regeneration in mice. Brain Res. 480, 300-304.

Venugopal, J., Low, S., Choon, A.T., and Ramakrishna, S. (2008). Interaction of cells and nanofiber scaffolds in tissue engineering. J. Biomed. Mater. Res. Part B Appl. Biomater. 84, 34-48.

Verdu, E., Labrador, R.O., Rodriguez, F.J., Ceballos, D., Fores, J., and Navarro, X. (2002). Alignment of collagen and laminincontaining gels improve nerve regeneration within silicone tubes. Restor. Neurol. Neurosci. 20, 169-179.

Wahl, D.A., and Czernuszka, J.T. (2006). Collagen-hydroxyapatite composites for hard tissue repair. Eur. Cells Mater. 11, 4356.

Wakitani, S., Goto, T., Young, R.G., Mansour, J.M., Goldberg, V.M., and Caplan, A.I. (1998). Repair of large full-thickness articular cartilage defects with allograft articular chondrocytes embedded in a collagen gel. Tissue Eng. 4, 429-444.

Wan, Y., Yu, A.X., Wu, H., Wang, Z.X., and Wen, D.J. (2005). Porous-conductive chitosan scaffolds for tissue engineering. II. In vitro and in vivo degradation. J. Mater. Sci. Mater. Med. 16, 1017-1028.

Wang, S., Wong Po Foo, C., Warrier, A., Poo, M.M., Heilshorn, S.C., and Zhang, X. (2009). Gradient lithography of engineered proteins to fabricate $2 \mathrm{D}$ and $3 \mathrm{D}$ cell culture environments. Biomed. Microdevices 11, 1127-1134.

Wang, X.D., Gu, X.S., Yuan, C.W., Chen, S.J., Zhang, P.Y., Zhang, T.Y., Yao, J., Chen, F., and Chen, G. (2004). Evaluation of biocompatibility of polypyrrole in vitro and in vivo. J. Biomed. Mater. Res. 68A, 411-422.

Wells, M.R., Kraus, K., Batter, D.K., Blunt, D.G., Weremowitz, J., Lynch, S.E., Antoniades, H.N., and Hansson, H.A. (1997). Gel matrix vehicles for growth factor application in nerve gap injuries repaired with tubes: A comparison of biomatrix, collagen, and methylcellulose. Exp. Neurol. 146, 395-402.

West, J.L., and Hubbell, J.A. (1999). Polymeric biomaterials with degradation sites for proteases involved in cell migration. Macromolecules 32, 241-244.

Willerth, S.M., and Sakiyama-Elbert, S.E. (2007). Approaches to neural tissue engineering using scaffolds for drug delivery. Adv. Drug Deliv. Rev. 59, 325-338.

Willerth, S.M., and Sakiyama-Elbert, S.E. (2008). Cell therapy for spinal cord regeneration. Adv. Drug Deliv. Rev. 60, 263-276.

Willerth, S.M., Arendas, K.J., Gottlieb, D.I., and Sakiyama-Elbert, S.E. (2006). Optimization of fibrin scaffolds for differentiation of murine embryonic stem cells into neural lineage cells. Biomaterials 27, 5990-6003.

Williams, L.R., Longo, F.M., Powell, H.C., Lundborg, G., and Varon, S. (1983). Spatial-temporal progress of peripheral nerve regeneration within a silicone chamber - parameters for a bioassay. J. Comp. Neurol. 218, 460-470.

Woerly, S., Doan, V.D., Sosa, N., de Vellis, J., and EspinosaJeffrey, A. (2004). Prevention of gliotic scar formation by 
NeuroGel (TM) allows partial endogenous repair of transected cat spinal cord. J. Neurosci. Res. 75, 262-272.

Wong Po Foo, C., Lee, J.S., Mulyasasmita, W., Parisi-Amon, A., Heilshorn, S.C. Two-component protein-engineered physical hydrogels for cell encapsulation. Proc. Acad. Sci. U.S.A. published online before print Dec. 10, 2009; doi:10.1073/ pnas.0904851106.

Wosnick, J.H., and Shoichet, M.S. (2008). Three-dimensional chemical patterning of transparent hydrogels. Chem. Mater. 20, 55-60.

Wylie, R.G., and Shoichet, M.S. (2008). Two-photon micropatterning of amines within an agarose hydrogel. J. Mater. Chem. 18, 2716-2721.

Xu, G., Nie, D.Y., Wang, W.Z., Zhang, P.H., Shen, J., Ang, B.T., Liu, G.H., Luo, X.G., Chen, N.L., and Xiao, Z.C. (2004). Optic nerve regeneration in polyglycolic acid-chitosan conduits coated with recombinant L1-Fc. Neuroreport 15, 2167-2172.

Xu, X.M., Guenard, V., Kleitman, N., and Bunge, M.B. (1995a). Axonal regeneration into schwann cell-seeded guidance channels grafted into transected adult rat spinal cord. J. Comp. Neurol. 351, 145-160.

Xu, X.M., Guenard, V., Kleitman, N., Aebischer, P., and Bunge, M.B. (1995b). A combination of BDNF and NT-3 promotes supraspinal axonal regeneration into Schwann cell grafts in adult rat thoracic spinal cord. Exp. Neurol. 134, 261-272.

Xu, X.M., Zhang, S.X., Li, H.Y., Aebischer, P., and Bunge, M.B. (1999). Regrowth of axons into the distal spinal cord through a Schwann-cell-seeded mini-channel implanted into hemisected adult rat spinal cord. Eur. J. Neurosci. 11, 17231740.

Yamaguchi, I., Itoh, S., Suzuki, M., Osaka, A., and Tanaka, J. (2003a). The chitosan prepared from crab tendons: II. The chitosan/apatite composites and their application to nerve regeneration. Biomaterials 24, 3285-3292.

Yamaguchi, I., Itoh, S., Suzuki, M., Sakane, M., Osaka, A., and Tanaka, J. (2003b). The chitosan prepared from crab tendon. I. The characterization and the mechanical properties. Biomaterials 24, 2031-2036.

Yang, F., Murugan, R., Wang, S., and Ramakrishna, S. (2005). Electrospinning of nano/micro scale poly(L-lactic acid) aligned fibers and their potential in neural tissue engineering. Biomaterials 26, 2603-2610.
Yang, Y.M., Gu, X.S., Tan, R.X., Hu, W., Hu, W., Wang, X.D., Zhang, P.Y., and Zhang, T.Y. (2004). Fabrication and properties of a porous chitin/chitosan conduit for nerve regeneration. Biotechnol. Lett. 26, 1793-1797.

Yoshii, S., Oka, M., Shima, M., Taniguchi, A., Taki, Y., and Akagi, M. (2004). Restoration of function after spinal cord transection using a collagen bridge. J. Biomed. Mater. Res. 70A, 569-575.

Young, R.C., Wiberg, M., and Terenghi, G. (2002). Poly-3hydroxybutyrate (PHB): A resorbable conduit for long-gap repair in peripheral nerves. Br. J. Plast. Surg. 55, 235-240.

Yu, L.M.Y., Kazazian, K., and Shoichet, M.S. (2007). Peptide surface modification of methacrylamide chitosan for neural tissue engineering applications. J. Biomed. Mater. Res. 82A, 243-255.

Yu, L.M.Y., Leipzig, N.D., and Shoichet, M.S. (2008). Promoting neuron adhesion and growth. Mater. Today 11, 36-43.

Yu, T.T., and Shoichet, M.S. (2005). Guided cell adhesion and outgrowth in peptide-modified channels for neural tissue engineering. Biomaterials 26, 1507-1514.

Yu, X.J., and Bellamkonda, R.V. (2001). Dorsal root ganglia neurite extension is inhibited by mechanical and chondroitin sulfate-rich interfaces. J. Neurosci. Res. 66, 303-310.

Zhang, S.G. (2003). Fabrication of novel biomaterials through molecular self-assembly. Nat. Biotechnol. 21, 1171-1178.

Zhang, Z.P., Yoo, R., Wells, M., Beebe, T.P., Biran, R., and Tresco, P. (2005). Neurite outgrowth on well-characterized surfaces: preparation and characterization of chemically and spatially controlled fibronectin and RGD substrates with good bioactivity. Biomaterials 26, 47-61.

Zhong, Y.H., and Bellamkonda, R.V. (2008). Biomaterials for the central nervous system. J. R. Soc. Interface 5, 957-975.

Address correspondence to: Sarah C. Heilshorn, Ph.D. Materials Science and Engineering Department Stanford University 476 Lomita Mall

McCullough Building, Room 246 Stanford, CA, 94305-4045

E-mail: heilshorn@stanford.edu 
